\title{
Global Emergence and Dissemination of Enterococci as Nosocomial Pathogens: Attack of the Clones?
}

\begin{abstract}
Ana M. Guzman Prieto ${ }^{1}$, Willem van Schaik', Malbert R. C. Rogers', Teresa M. Coque ${ }^{2,3,4}$, Fernando Baquero ${ }^{2,3,4}$, Jukka Corander ${ }^{5}$ and Rob J. L. Willems ${ }^{1 *}$

${ }^{1}$ Department of Medical Microbiology, University Medical Center Utrecht, Utrecht, Netherlands, ${ }^{2}$ Hospital Universitario Ramon y Cajal, Instituto Ramón y Cajal de Investigación Sanitaria, Madrid, Spain, ${ }^{3}$ CIBER Epidemiología y Salud Pública, Madrid, Spain, ${ }^{4}$ Unidad de Resistencia a Antibióticos y Virulencia Bacteriana Asociada al Consejo Superior de Investigaciones Cientificas, Madrid, Spain, ${ }^{5}$ Department of Mathematics and Statistics, University of Helsinki, Helsinki, Finland
\end{abstract}

Enterococci are Gram-positive bacteria that are found in plants, soil and as commensals of the gastrointestinal tract of humans, mammals, and insects. Despite their commensal nature, they have also become globally important nosocomial pathogens. Within the genus Enterococcus, Enterococcus faecium, and Enterococcus faecalis are clinically most relevant. In this review, we will discuss how E. faecium and E. faecalis have evolved to become a globally disseminated nosocomial pathogen. E. faecium has a defined sub-population that is associated with hospitalized patients and is rarely encountered in community settings. These hospital-associated clones are characterized by the acquisition of adaptive genetic elements, including genes involved in metabolism, biofilm formation, and antibiotic resistance. In contrast to $E$. faecium, clones of $E$. faecalis isolated from hospitalized patients, including strains causing clinical infections, are not exclusively found in hospitals but are also present in healthy individuals and animals. This observation suggests that the division between commensals and hospital-adapted lineages is less clear for E. faecalis than for E. faecium. In addition, genes that are reported to be associated with virulence of $E$. faecalis are often not unique to clinical isolates, but are also found in strains that originate from commensal niches. As a reflection of more ancient association of $E$. faecalis with different hosts, these determinants Thus, they may not represent genuine virulence genes but may act as host-adaptive functions that are useful in a variety of intestinal environments. The scope of the review is to summarize recent trends in the emergence of antibiotic resistance and explore recent developments in the molecular epidemiology, population structure and mechanisms of adaptation of $E$. faecium and $E$. faecalis.

Keywords: E. faecium, E. faecalis, high-risk nosocomial clones, antibiotic resistance, virulence

\section{INTRODUCTION}

Enterococci are low-GC Gram-positive ovococci that can form pairs and chains of diverse lengths. Bacteria from the genus Enterococcus are facultative anaerobic and grow optimally at $35^{\circ} \mathrm{C}$, but can tolerate temperatures ranging from $10^{\circ} \mathrm{C}$ to $45^{\circ} \mathrm{C}$ (Byappanahalli et al., 2012). The genus comprises 54 species (Parte, 2014), which are ubiquitously present in nature but the gastrointestinal tract (GIT) 
of animals, including mammals, reptiles, birds (Mundt, 1963a) and insects (Martin and Mundt, 1972), is thought to be the largest reservoir of enterococci (Gilmore et al., 2013).

In humans, enterococci are common commensals of the GIT. In addition, enterococci have become ever more prominent as a causative agent of nosocomial infections since the 1970s (Arias and Murray, 2012). Two species, Enterococcus faecalis and Enterococcus faecium, cause the vast majority of hospitalacquired enterococcal infections in humans (Agudelo Higuita and Huycke, 2014). Of these two, E. faecium has rapidly acquired resistance to several classes of antibiotics. First, in the 1970s and 1980s, E. faecium gained high-level resistance to ampicillin (Grayson et al., 1991; Galloway-Peña et al., 2009) and since the 1980s it acquired resistance to aminoglycosides, fluoroquinolones, and glycopeptides, particularly vancomycin (Leclercq et al., 1988; Uttley et al., 1988; National Nosocomial Infections Surveillance System, 2004). E. faecalis has also acquired resistance to aminoglycosides, but resistance to ampicillin and vancomycin is much rarer than in E. faecium (Edelsberg et al., 2014). Worryingly, resistance to antibiotics that are used to treat vancomycin resistant enterococci (VRE), like linezolid, tigecycline, and daptomycin, has already been reported (Aksoy and Unal, 2008; Montero et al., 2008; Scheetz et al., 2008; Niebel et al., 2015).

The intrinsic resistance of enterococci to some antibiotics, including aminoglycosides, and the ability to acquire and disseminate antibiotic resistance determinants, like those involved in vancomycin resistance, only partly explain the recent emergence of these organisms as nosocomial pathogens. In addition, the plasticity of the enterococcal genomes allow enterococci to rapidly respond and adapt to selective constraints by acquiring genetic determinants that increase their ability to colonize or infect the host (Hendrickx et al., 2009; Palmer et al., 2012; Lebreton et al., 2013; Van Tyne and Gilmore, 2014). Other host or environmental factors, most notably exposure to antimicrobial agents, may favor an increase in colonization density of enterococci in the GIT of hospitalized patients (Donskey et al., 2000; Ubeda et al., 2010; Ruiz-Garbajosa et al., 2012). Antibiotic therapy that leads to the depletion of Gramnegatives, can reduce production of the antimicrobial peptide REGIII $\gamma$ by Paneth cells, and this may promote the outgrowth of VRE (Brandl et al., 2008).

Patients undergoing transplants or with underlying diseases, such as diabetes or renal failure, and patients with long-term catheter usage, are at higher risk of developing infections caused by multi-drug resistant (MDR) enterococci (Arias and Murray, 2012). High-density colonization of the patient GIT facilitates the transmission of MDR enterococci among hospital ward through fecal contamination (Arias and Murray, 2012). Therefore epidemiological surveillance and outbreak investigations, together with infection control polices and interventions, such as the use of protective barriers and proper disinfection, are key for infection control of these organisms in the nosocomial environment (Sydnor and Perl, 2011). Highlevel enterococcal GIT colonization can also lead to urinary tract infections (UTI) (De Vecchi et al., 2013; Neelakanta et al., 2015), which may progress to bloodstream infections or endocarditis (Patterson et al., 1995; Fernández-Guerrero et al., 2002). Enterococci from high-density intestinal populations may also directly translocate from the GIT into the bloodstream (Kamboj et al., 2014).

Enterococci have become one of the most common causes of health care-associated infections with E. faecalis causing approximately $60 \%$ of infections and E. faecium the remainder (de Kraker et al., 2013; Sievert et al., 2013). This review will focus on E. faecalis and E. faecium as both species have emerged as important nosocomial pathogens over the last 30 years and represent a major hub for the dissemination of antibiotic resistance genes.

\section{EMERGENCE OF ANTIBIOTIC RESISTANCE IN ENTEROCOCCI}

Enterococcus faecalis and E. faecium exhibit intrinsic resistance to a broad range of antibiotics. Below we briefly describe the mechanisms that cause resistance to the classes of antibiotics that are currently used in the treatment of enterococcal infections.

Compared to other low-GC Gram-positive cocci, enterococci exhibit decreased susceptibility to $\beta$-lactam antibiotics. The $\beta$-lactams act through the inactivation of penicillinbinding proteins (PBPs), thereby interfering with synthesis of peptidoglycan. All enterococci display decreased susceptibility to $\beta$-lactam antibiotics due to the expression of PBPs with an intrinsic low affinity for this class of antibiotics. Resistance to $\beta$-lactams, most notably to ampicillin, is currently far more widespread in E. faecium than in E. faecalis (Cattoir and Giard, 2014). The most important determinants for $\beta$-lactam resistance in E. faecium are mutations in the genes encoding the PBP5 (Zorzi et al., 1996; Rice et al., 2001; Zhang et al., 2012). There are clear indications that E. faecium progressed toward highlevel ampicillin resistance in the 1970s and 1980s through the acquisition of specific mutations in the $p b p 5$ gene (Grayson et al., 1991; Galloway-Peña et al., 2009, 2011). It is of importance to note that these chromosomally encoded PBPs can be transferable (Dahl et al., 2000; Hanrahan et al., 2000; Rice et al., 2005), which indicates that dissemination of high-level ampicillin resistance can be the result of both clonal spread of strains with mutated $p b p 5$ genes and horizontal gene transfer. In addition to mutations in $p b p 5$, production of $\beta$-lactamase has been described in both E. faecalis and E. faecium (Tomayko et al., 1996; Sarti et al., 2012). In general, the expression level of beta-lactamase in these species is low and impact on ampicillin susceptibility marginal.

Another group of antibiotics to which E. faecium and E. faecalis exhibit moderate intrinsic and high-level acquired resistance are the aminoglycosides. In E. faecalis, intrinsic resistance is thought to be caused by the inability of the antibiotic to enter the cytoplasm and inhibit ribosomal protein synthesis (Aslangul et al., 2006). In E. faecium, two chromosomally encoded genes, a $6^{\prime}-N$-aminoglycoside acetyltransferase $\left(\operatorname{aac}\left(6^{\prime}\right)\right.$ Ii) (Costa et al., 1993) and an rRNA methyltransferase (efmM) (Galimand et al., 2011), have been associated with intrinsic resistance to tobramycin and kanamycin. In addition to intrinsic resistance to aminoglycosides, the therapeutic 
success of these antibiotics is critically compromised by highlevel resistance, due to the gain of aminoglycoside modifying enzymes, such as phosphotransferases, acetyltransferases, and nucleotidyltransferases by E. faecium and E. faecalis (Chow, 2000; Miller et al., 2014).

The assessment of enterococci, particularly E. faecium, as important agents of MDR nosocomial infections was definitively established when they acquired resistance to vancomycin. While vancomycin-resistant enterococci were virtually nonexistent in hospitals in the USA before 1990, nowadays $87 \%$ of E. faecium strains from nosocomial infections are vancomycin-resistant, while this is only $14 \%$ for E. faecalis (Edelsberg et al., 2014). Vancomycin is a glycopeptide antibiotic, which prevents cross-linking of peptidoglycan by binding to the D-alanine-D-alanine (D-Ala-D-Ala) moiety of the peptide chains that crosslink peptidoglycans. The mechanisms by which enterococci become resistant to vancomycin have been extensively reviewed elsewhere (Courvalin, 2006). In short, enterococci become resistant to vancomycin when the terminal amino acids of peptidoglycan precursors are altered from D-AlaD-Ala to D-Ala-D-lactate (D-Ala-D-Lac) or to D-Ala-D-Serine (D-Ala-D-Ser), leading to high-level and low-level resistance to vancomycin, respectively. Nine gene clusters are currently known to be involved in vancomycin resistance in enterococci. These vancomycin resistance gene clusters are $\operatorname{van} A, \operatorname{van} B, \operatorname{van} D$, and van $M$, causing vancomycin resistance through the formation of D-Ala-D-Lac, and vanC, vanE, vanG, vanL, and vanN which catalyze the formation of D-Ala-D-Ser (Courvalin, 2006; Boyd et al., 2008; Xu et al., 2010; Lebreton et al., 2011). The most frequently found, and thus clinically most relevant, vancomycin resistance determinants are $v a n A$ and $v a n B$, which are both part of larger gene clusters, which encode a two-component regulatory system and enzymes involved in the recycling of D-Ala-D-Ala peptidoglycan precursors to D-Ala-D-Lac. Both vanA and vanB are located on transposons that contribute to the dissemination of vancomycin resistance among enterococci (Courvalin, 2006). Recently, vanM was found to be the most important vancomycinresistance determinant among different E. faecium lineages in hospitals in Shanghai, China (Chen et al., 2015). Differences in the sequence diversity and prevalence of each van operon could be due to the different ecological origins of the van clusters. While van $A$ seems to have originated from soil organisms, $\operatorname{van} B, \operatorname{van} G$, and $v a n D$ have been reported in gut commensal microbiota (Guardabassi et al., 2005; Domingo et al., 2007; Howden et al., 2013).

While vancomycin resistance emerged and spread in USA hospitals in the 1990s, carriage of vancomycin-resistant E. faecium (VREF) was rare among hospitalized patients in Europe. In contrast, VRE carriage among farm animals, and, to a lesser extent, in healthy humans was higher in Europe than in the USA (Klare et al., 1995; Devriese et al., 1996; Stobberingh et al., 1999). The widespread occurrence of VRE among farm animals was linked to the use of the vancomycin-analog avoparcin as a growth promoter in Europe (Bager et al., 1997). The presence of indistinguishable vancomycin resistance transposons in both animal and human reservoirs provided the first indication that animal-derived enterococci could be a reservoir of antibiotic resistance genes that could be transmitted to humans (Arthur et al., 1993; Jensen et al., 1998; Woodford et al., 1998; Willems et al., 1999). After the ban on the use of avoparcin in 1997, the prevalence of VRE in animal husbandry declined in Europe (Klare et al., 1999; van den Bogaard et al., 2000; Aarestrup et al., 2001). In several European countries, the prevalence of VRE among hospitalized patients increased in the 21st century, but is still lower than the endemic levels reported in US hospitals (Bourdon et al., 2011; Gastmeier et al., 2014; Pinholt et al., 2015; Simner et al., 2015). Levels of VRE among hospitalized patients are also high in Australia, with $37 \%$ of E. faecium bacteremia isolates exhibiting resistance to vancomycin. Interestingly, vancomycin resistance in Australian E. faecium isolates is almost exclusively caused by van $B$-type transposons, while vanA is the major vancomycin-resistance determinant in Europe and the USA (Coombs et al., 2014).

Due to the emergence and rapid spread of VRE, the antibiotics linezolid, daptomycin and tigecycline are increasingly used for the treatment of VRE infections.

Linezolid, the first oxazolidinone antibiotic, was introduced for clinical use in the USA in 2000. It acts on the ribosome by binding to a universally conserved site on $23 \mathrm{~S}$ rRNA of the large 50S subunit of the ribosome (Colca et al., 2003), thereby inhibiting elongation of the polypeptide chain. The currently described linezolid resistance mechanisms alter the peptidyl transferase center of $23 \mathrm{~S}$ rRNA, by a mutation in the $23 \mathrm{~S}$ rRNA gene, with the G2576T mutation being most prominent (Jones et al., 2008), mutations in the genes encoding ribosomal proteins L3 and L4 (Chen et al., 2013) or methylation of the adenine at position 2503 , which is catalyzed by the methyltransferase Cfr. The $c f r$ gene is encoded on various conjugative and nonconjugative plasmids in enterococci (Diaz et al., 2012; Shen et al., 2013). Recently, the oxazolidinone resistance gene optrA has been identified in E. faecalis and E. faecium isolates of human and animal origin (Cai et al., 2015; Wang et al., 2015). This gene codes for an ATP-binding cassette transporter, which contributes to reduced susceptibility for oxazolidinones (linezolid and tedizolid) and phenicols (chloramphenicol and florfenicol). The optrA gene was associated with a conjugative plasmid (Wang et al., 2015). Nevertheless, linezolid resistance is still rare. In a study using data from 19 US hospitals in the period 2007-2010, linezolid resistance was reported in 1.1 and $1.8 \%$ of E. faecium and E. faecalis isolates, respectively (Edelsberg et al., 2014).

Daptomycin is a lipopeptide antibiotic that targets the cell membrane through interactions with phospholipids (Humphries et al., 2013). The genetic basis for resistance in E. faecalis and E. faecium was first studied through genome sequencing of pairs of strains that developed resistance in vitro or in vivo (Arias et al., 2011; Palmer et al., 2011; Tran et al., 2013a). Additional genetic and biochemical work has established the role of the three-component regulatory system LiaFSR in contributing to daptomycin resistance in enterococci. The LiaFSR system is conserved in low-GC Gram-positive bacteria and governs the cell envelope stress response (Jordan et al., 2006). Mutations in the $l i a F$ gene of $E$. faecalis lead to a redistribution of cardiolipin-rich microdomains from the division septum to other regions of the 
cytoplasmic membrane, which affects the antimicrobial activity of daptomycin. In addition, other mutations in phospholipid biosynthesis genes, most notably in the cardiolipin synthase gene $c l s$, are required for full expression of daptomycin resistance in E. faecalis (Davlieva et al., 2013; Tran et al., 2013b). Similar mechanisms have been associated with daptomycin resistance in E. faecium (Munita et al., 2012, 2014; Davlieva et al., 2013). Notably, emergence of daptomycin resistance in E. faecium during daptomycin therapy is not always linked to mutations in liaFSR and mutations in cls may already be sufficient (Kelesidis et al., 2013; Lellek et al., 2015). Daptomycin resistance is infrequent, but more common in E. faecium than in E. faecalis. A worldwide study in isolates from hospitalized patients over the period 2005-2012 showed levels of daptomycin resistance of $0.18 \%$ for E. faecium and $0.02 \%$ for E. faecalis (Sader et al., 2014). However, in certain settings daptomycin resistance may be considerably more frequent, as illustrated by a study including 4,274 E. faecium and 7,007 E. faecalis isolates from 19 US hospitals, which found daptomycin resistance among 3.9 and $0.2 \%$ of E. faecium and E. faecalis isolates, respectively (Edelsberg et al., 2014). Similar levels of daptomycin resistance in E. faecium were recently reported for a German hospital (Lübbert et al., 2015).

Tigecycline is a semisynthetic derivative of the broadspectrum tetracycline antibiotic minocycline, which acts on the ribosome by inhibiting its association with aminoacyl-tRNAs. The emergence of resistance during tigecycline therapy was first observed in E. faecalis (Werner et al., 2008; Cordina et al., 2012) and has recently been described in E. faecium (Niebel et al., 2015). In enterococci, resistance to tigecycline can be mediated through upregulation of tetracycline resistance determinants tet $L$ (encoding an efflux pump) and tet $M$ (providing ribosomal protection) (Fiedler et al., 2015) and mutations in the ribosomal protein rpsJ (Beabout et al., 2015; Cattoir et al., 2015; Niebel et al., 2015). Tigecycline resistance among E. faecium and E. faecalis is rare at $0.3 \%$ for both species (Hoban et al., 2015) and the antibiotic can still be used successfully to treat bacteremias caused by MDR enterococci, especially when it is used in combination with daptomycin (Polidori et al., 2011). The recovery of enterococcal isolates with decreased susceptibility to tigecycline in samples of animal origin is of concern, as extensive use with tetracyclines in the veterinary setting could select for tigecycline tolerant strains (Freitas et al., 2011).

In addition to the antibiotics described above, the antibiotics tedizolid, telavancin, dalbavancin, and oritavancin have recently been approved by the Food and Drug Administration in the USA for the treatment of skin infections by Gram-positive bacteria (Crotty et al., 2016). Tedizolid is an oxazolidinone antibiotic that has improved in vitro activity compared to linezolid. Enterococcal strains that have acquired linezolid resistance due to the acquisition of the $c f r$ gene or the G2576T mutation in the $23 \mathrm{~S}$ rRNA gene, may still have relatively low MICs $(\leq 4 \mu \mathrm{g} / \mathrm{ml}$ ) for tedizolid (Barber et al., 2016; Silva-Del Toro et al., 2016). Telavancin, dalbavancin and oritavancin are semisynthetic glycopeptides antibiotics that, similar to vancomycin, affect peptidoglycan stability by binding to the D-Ala-D-Ala moiety of the peptide chains that crosslink peptidoglycan chains.
Interestingly, oritavancin is also active against $v a n A$ - and $v a n B$ type vancomycin-resistant enterococci, while telavancin and dalbavancin have limited activity against enterococci carrying the vanA-type vancomycin resistance transposon but are active against enterococci with vanB-type vancomycin resistance (Jones et al., 2013; Karlowsky et al., 2015). Tedizolid, telavancin, dalbavancin, and oritavancin may be useful as alternatives to linezolid and vancomycin, but they do not have radically different modes of action and they may therefore suffer from the same resistance mechanisms that are threatening the efficacy of linezolid and vancomycin. Therefore, antibiotics that target other structures in the enterococcal cell, including teixobactin (Ling et al., 2015) and the acyldepsipeptides (Brötz-Oesterhelt et al., 2005), hold considerable promise as novel compounds for the treatment of infections with MDR enterococci.

\section{MOLECULAR EPIDEMIOLOGY AND POPULATION STRUCTURE OF E. faecium AND E. faecalis}

\section{E. faecium}

As a consequence of the global rise of VREF, a large number of molecular epidemiological studies have been performed to obtain insights into the dissemination of VREF clones in and between hospitals, in farm animals and healthy humans. However, methods like pulse-field gel electrophoresis (PFGE), soon proved to be insufficiently reproducible to study genetic relatedness of isolates (Morrison et al., 1999).

A first insight into the existence of particular ecotypes in E. faecium, was obtained by using amplified fragment polymorphism (AFLP) to infer the genetic relatedness of strains from diverse hosts and environments (Willems et al., 2000). This study revealed that strains from hospitalized patients grouped in a specific sub-population that was distinct from groups of strains that were isolated from humans in the community and farm animals.

The use of AFLP for global studies showed the limitations of this technique for comparisons of data obtained from different laboratories. Therefore an alternative method, termed multi locus sequence typing (MSLT), was used in follow-up studies. In MLST, allelic profiles are based on the sequences of fragments of a number of housekeeping genes (seven in the case of the E. faecium and E. faecalis MLST schemes) (Homan et al., 2002; Ruiz-Garbajosa et al., 2006). Compared to AFLP, MLST has the distinct advantage that data are easily collated and shared through an on-line database. The first analyses of E. faecium MLST data were performed with the algorithm eBurst (Feil et al., 2004) and confirmed a distinct clustering of strains derived from the hospital environment. This cluster was named clonal complex 17 (CC17) and soon CC17 was found to be disseminated throughout the world (Willems et al., 2005; Top et al., 2008). The later use of larger datasets and different algorithms for the analysis of MLST data (Didelot and Falush, 2007; Francisco et al., 2009), showed that eBurst can sometimes fail to correctly assign STs to clonal complexes (CCs), particularly when genetic variation 
in populations is largely driven by recombination rather than mutations, like is the case in E. faecium and E. faecalis (Turner et al., 2007).

Bayesian analysis of population structure (BAPS) has successfully been used to probabilistically infer the population structure and levels of recombination of several microbial pathogens (Corander et al., 2012; Thomas et al., 2014). When applied to E. faecium MLST data, BAPS allowed the partitioning of 519 STs of 1720 E. faecium isolates into 13 non-overlapping groups. Of these groups, BAPS 3-3 was significantly associated with isolates from hospitalized patients, while BAPS $2-1$ and 2-4 were significantly associated with farm animals. This observation again confirmed that there exists structure in the E. faecium population, with a distinct subpopulation of isolates that are almost exclusively found in hospitalized patients (Willems et al., 2012). One of the important nodes in the previously described hospital-associated CC17, ST78, and its descendant STs, grouped in BAPS 2-1 together with farm animal isolates, while two other important CC17 nodes, ST17 and ST18 with their descendant STs, clustered in another BAPS group (BAPS 3-3). These findings indicate that nosocomial E. faecium isolates have not evolved from a single ancestor, like previously postulated, but rather the cumulative acquisition of adaptive elements in nosocomial isolates may have occurred multiple times in different genetic backgrounds. Another conclusion that could be drawn from Bayesian modeling of MLST data is that hospital isolates displayed a relative low-level of admixture, despite the high recombination rates in E. faecium, suggesting that once strains have adapted to the distinct hospital niche, they become ecologically isolated (including isolation by dominance) and recombination with other populations declines (Willems et al., 2012).

Despite the overt lack of reproducibility, PFGE long remained the "gold standard" for molecular typing of E. faecium until the introduction of whole genome sequence (WGS)-based epidemiology. Howden et al. (2013) published a landmark study in which they used whole genome sequencing to track an outbreak of vanB-VREF in a large hospital in Australia. Interestingly, detailed phylogenomic analysis and precise mapping of the $\operatorname{van} B$ gene revealed that 18 of the $36 \mathrm{van} B$ VREF had acquired the vanB transposon during the outbreak period. This indicates that for vanB-VREF, frequent de novo generation of VREF through horizontal gene transfer may contribute to the emergence of VREF, in addition to clonal spread. This study was followed by multiple other studies that used whole genome sequencing to investigate the molecular epidemiology of VREF with high resolution and high accuracy (Reuter et al., 2013; Salipante et al., 2015; Brodrick et al., 2016; van Hal et al., 2016). Bender et al. (2016) performed whole genome sequencing of 49 vanB-VREF, primarily of ST192 (39/49), from invasive infections from hospitals all across Germany and found that spread of the Tn1549-vanB-type resistance involved exchange of large chromosomal fragments between $v a n B$-positive and $v a n B$-negative enterococci rather than independent acquisition events of the van $B$ transposon alone.
WGS-based studies also proposed that the E. faecium population was divided into two species-level subdivisions, based on phylogenetic analysis and the determination of average nucleotide identity (ANI) between the two sub-populations. The sub-populations were termed clade A or hospital-associated clade, primarily containing isolates from hospitalized patients and clade B or community-associated clade, mostly containing isolates from healthy, non-hospitalized individuals (GallowayPeña et al., 2012; Palmer et al., 2012). The high level of diversity between these two clades indicates that the clade AB split is ancient and precedes the modern antibiotic era. Further work provided further evidence for this split and showed that the population of E. faecium in clade A had a second split of more recent date $(74 \pm 30$ years), with clade A1 containing the majority of clinical isolates and clade A2 mostly comprising animal-derived strains (Lebreton et al., 2013). WGS also confirmed that E. faecium was subject to high rates of recombination, leading to changes in MLST profile in otherwise closely related strains, which invalidates the use of MLST for tracking transmission events (van Hal et al., 2016). Another finding of van Hal et al. (2016) was that other E. faecium strains are the most important donors of imported DNA fragments. Specifically, strains from clade $B$ are an important reservoir for donating foreign DNA to clade A strains (de Been et al., 2013). These findings indicate that hospital-acquired clade A1 E. faecium strains have recently emerged from a background of human commensal and animal isolates. Tree-like network representations of E. faecium genomic relatedness based on cgMLST data also revealed the distinct clustering of human commensal, animal and human clinical strains (Figure 1). Notably, in this analysis the animal isolates do not group in a single clade A2 but form multiple distinct clusters that are located in the network, between the human commensal and clinical isolates, indicating that clade A2 may not be monophyletic, as previously postulated (Lebreton et al., 2013). Interestingly, clade A1 E. faecium strains have lower fitness in natural environments, where they are out-competed by other E. faecium clones (Leclercq et al., 2013). Similarly, clade B strains outcompete clade A strains in an animal model of gut colonization in the absence of selection by antibiotics (Montealegre et al., 2015). These data highlight the exquisite niche specialization to the hospital environment of clade A1 strains, which may come at a fitness cost in non-hospital environments.

The WGS-based epidemiological studies described above generated phylogenetic trees based on SNPs, by mapping sequencing reads to a reference genome. This approach, although providing high-resolution typing data, complicates comparisons of data between studies and hampers the construction of globally accessible databases. This limitation may be overcome by using a genome-wide gene-by-gene comparison approach, as in classical MLST, but with an important extension of the number of analyzed genes from seven to the entire core genome of the species, i.e., 1423 genes as in the recently published core genome MLST (cgMLST) scheme of E. faecium (de Been et al., 2015). The E. faecium cgMLST scheme 


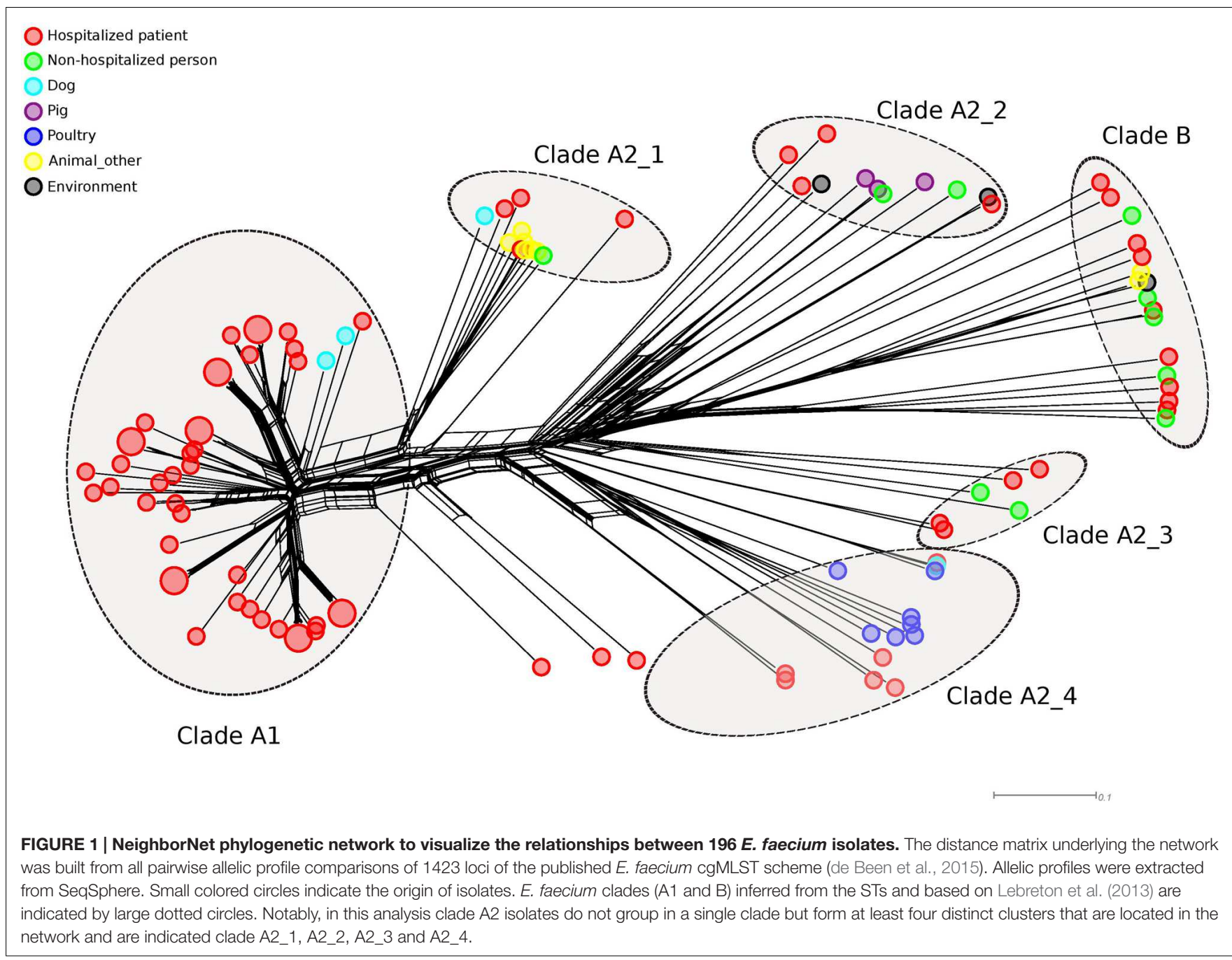

allowed high-resolution tracing of E. faecium outbreaks and performed equally well as an SNP-based phylogenetic approach, but has the advantage that data can be collated in an online database and a standardized nomenclature for clones can be used.

\section{E. faecalis}

Enterococcus faecalis appears to be the most widespread and abundant species of Enterococcus and can be found in the intestines of humans, farm, companion, and wild animals and in the environment (Mundt, 1963a,b; Devriese et al., 1992a,b; Tannock and Cook, 2002; Ruiz-Garbajosa et al., 2009). Initial molecular epidemiological studies, using MLST, showed the existence of CCs, in which isolates originating from different hosts are contained (Ruiz-Garbajosa et al., 2006; McBride et al., 2007). While many E. faecalis clones are shared between hospitalized patients and other reservoirs, some CCs (specifically CC2, CC9, and CC87) and STs (ST6 and ST16) seemed to be enriched among isolates from hospitalized patients (RuizGarbajosa et al., 2006; McBride et al., 2007; Freitas et al., 2009; Kuch et al., 2012). Similarly, in isolates collected from across the globe, antibiotic resistance is more prevalent in strains that belong to CC2, CC8, CC9, CC16, and CC87 (Kawalec et al., 2007; McBride et al., 2007; Freitas et al., 2009; Kuch et al., 2012).

Analysis of the extent of congruence between the topologies of the seven different MLST gene trees revealed that that all 42 pairwise comparisons of the sequences of the MLST loci were incongruent. This observation suggests that E. faecalis is a highly recombinogenic species (Ruiz-Garbajosa et al., 2006). For this reason Tedim et al. (2015) used BAPS to investigate the E. faecalis population structure based on MLST data of hospitalized $(n=133)$ and non-hospitalized individuals ( $n=173$ ) isolated from feces. A hierarchical BAPS clustering analysis partitioned the E. faecalis population into 5 BAPS groups. Contrary to what has been described in E. faecium and to eBURST based analyses of E. faecalis MLST data, no significant association was found between isolates from hospitalized patients and particular E. faecalis BAPS groups (Tedim et al., 2015).

The first comprehensive E. faecalis phylogenomic study involved 18 E. faecalis genomes representing clinical $(n=10)$, 
human commensal $(n=3)$, and animal isolates $(n=3)$, and isolates of unknown origin $(n=2)$ (Palmer et al., 2012). The analysis revealed that the phylogenetic diversity of E. faecalis was limited compared to E. faecium, with variations in the ANI in a narrow range between 97.8 and $99.5 \%$. There was also no clear structure in the phylogenetic core gene tree, with no distinct clustering of isolates according to source. Similarly, clustering of these 18 isolates supplemented with 3 other published E. faecalis genomes from a clinical site, human feces and pig based on an ad hoc developed E. faecalis cgMLST scheme using tree-like network methods also revealed no distinct clustering of isolates according to their source (Figure 2). A recent genome-based study of 515 E. faecalis genomes, mainly isolated from clinical settings on the British Isles, revealed three dominant lineages of hospitalassociated lineages (L1, L2, and L3). Isolates in L1 and L3 originated from both the UK and USA (Raven et al., 2016). These data clearly indicate independent clonal expansion with subsequent national dissemination. The data may also point toward the existence of specific hospital-associated or hospitaladapted lineages. However, in order to unequivocally infer hospital-adapted lineages it is essential to correct the data for clonal outbreaks, by including outbreak clones only once in the analysis. The fact that only a limited number of STs (3, 2, and 2 STs in lineage 1, 2, and 3, respectively) were represented in these three lineages may suggest that these lineages contain multiple replicates of outbreaks clones. Analyses for recombination frequencies in the core genome of L1, L2 and L3 isolates indicated low levels of recombination, which seems to contrast with previous MLST-based analyses (Ruiz-Garbajosa et al., 2006; Raven et al., 2016). Possibly, recombination drove the initial diversification of E. faecalis but contributed less to the relatively recent evolution of the three dominant E. faecalis lineages described by Raven and co-workers (Raven et al., 2016).

\section{ADAPTIVE ELEMENTS IN NOSOCOMIAL LINEAGES}

Enterococci are ubiquitous in nature, where they act as commensals and opportunistic pathogens. A consequence of these different lifestyles is that enterococci need to adapt to different micro-environments, each one exerting strong selective pressures. A strategy for bacterial species to survive when confronted with a wide range of selective pressures is to specialize in particular fitness peaks. E. faecium probably followed such an evolutionary trajectory, resulting in the emergence of specific hospital-adapted lineages. Successful hospital-adapted clones in E. faecium have the ability to exchange mobile genetic elements, carrying antimicrobial resistance, and virulence determinants, by horizontal gene transfer (Leavis et al., 2003; Hegstad et al., 2010; Palmer et al., 2010; van Schaik et al., 2010). The cumulative acquisition of adaptive elements has been named "genetic capitalism", in which the acquisition of a particular adaptive element by a particular clone enhances its fitness, thereby increasing the likelihood of acquiring a second adaptive element which finally can lead to the emergence of high-risk multidrugresistant clones (Baquero, 2004). This cumulative acquisition of adaptive elements by the hospital-associated E. faecium clade A1 strains is reflected by their larger genome sizes $(2,843 \pm 159$ genes; $2.98 \pm 0.15 \mathrm{Mbp}$ ), compared to the genomes of strains in clade A2 (2,597 \pm 153 genes; $2.75 \pm 0.14 \mathrm{Mbp})$ or clade B (2,718 \pm 120 genes; $2.84 \pm 0.1 \mathrm{Mbp})$ (Lebreton et al., 2013).

The first adaptive element that was described as being specific for hospital-associated E. faecium strains was Esp (Willems et al., 2001), a surface protein with a signal sequence for transport and a LPxTG-like motif for cell wall anchoring. The E. faecium esp gene is located on an integrative conjugative element, called ICEEfm1, and contributes to biofilm formation, and UTIs and endocarditis in animal models (Leavis et al., 2004; Heikens et al., 2007, 2011; Leendertse et al., 2009; Sava et al., 2010; van Schaik et al., 2010; Top et al., 2011).

In addition to Esp, other determinants were found to be specific or significantly enriched among hospital-associated isolates. Characteristics of these genes have been previously discussed (Leavis et al., 2003; Heikens et al., 2008; Hendrickx et al., 2009, 2013; Zhang et al., 2013; Paganelli et al., 2016). Comparative genomic analyses of $73 \mathrm{E}$. faecium strains revealed major differences in gene content between clinical (clade A1), animal (clade A2) and non-clinical (clade B) strains, particularly through gain and loss of gene clusters with predicted roles in carbohydrate metabolism (Kim and Marco, 2013; Lebreton et al., 2013). Many of the clade B-specific genes have a predicted role in the utilization of complex carbohydrates from dietary sources, which were replaced with genes that were associated with the utilization of amino sugars (e.g., galactosamine), which occur on epithelial cell surfaces and in mucin. This metabolic switch may have contributed to the niche specialization of E. faecium.

As mentioned above the population structure of E. faecalis seems to be significantly different from E. faecium as no clearly defined E. faecalis ecotypes appear to exist. Correspondingly, previous studies have reported shared antibiotic resistance and virulence genes, such as the E. faecalis pathogenicity island, esp, capsule polysaccharide genes, and genes encoding for gelatinase, aggregation substance, cytolysin, and Ace, among E. faecalis isolates from a wide variety of different niches like the hospital, animals, food products and the environment (Eaton and Gasson, 2001; Creti et al., 2004; McBride et al., 2007; Freitas et al., 2009; Solheim et al., 2009; La Rosa et al., 2015). Note that the absence of clearly defined ecotypes in E. faecalis can be interpreted as a high multiplicity of closely related fine-grained ecotypes, none of them reaching predominance.

Comparative genomic analysis of 18 E. faecalis genomes showed that the accretion of mobile genetic elements in multiple E. faecalis lineages appears to be a major source of genome diversity (Palmer et al., 2012). Although antibiotic resistance and pathogenicity island traits have converged in some E. faecalis lineages, substantial differences in gene content exist, indicating that specialization toward specific ecotypes is not apparent in this species, in contrast to E. faecium. In addition, a hierarchical 


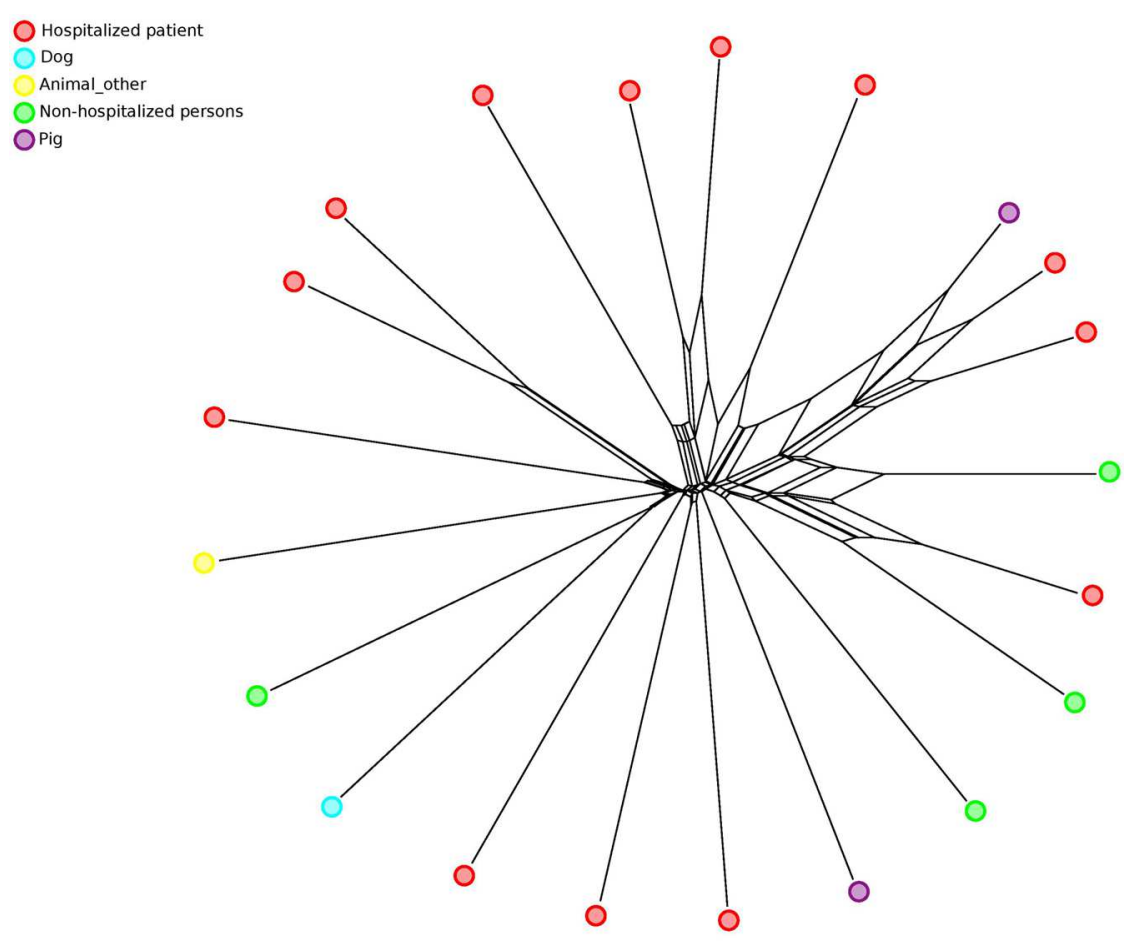

FIGURE 2 | NeighborNet phylogenetic network to visualize the relationships between 21 E. faecalis isolates. The distance matrix underlying the network was built from all pairwise allelic profile comparisons of 1298 loci of an ad hoc E. faecalis cgMLST scheme using SeqSphere (http://www.ridom.de/seqsphere/). Small colored circles indicate the origin of isolates.

clustering based on genome content of $38 \mathrm{E}$. faecalis genomes from diverse sources including clinical and non-clinical isolates, unearthed no evidence of distinct lineages in E. faecalis and no genes were found to be significantly enriched among clinical or non-clinical strains (Kim and Marco, 2013). A pangenome analysis of $168 \mathrm{E}$. faecalis isolates revealed no genes, or even homoplastic non-synonymous single nucleotide polymorphisms, that were ubiquitous in the three dominant lineages of hospital isolates, while being absent from all other sporadic lineages (Raven et al., 2016). These observations are all in accordance with high levels of genetic exchange between ecologically diverse E. faecalis clones.

In bacteria, mechanisms that preclude the acquisition of foreign DNA, include the Clustered Regularly Interspaced Short Palindromic Repeats (CRISPR)-Cas system (Horvath and Barrangou, 2010) and restriction and anti-restriction modification (RM-, antiRM-) systems (Clewell et al., 2014). E. faecalis strains lacking CRISPR-Cas appear to more readily acquire DNA through horizontal gene transfer and, consequently have a larger genome size than E. faecalis strains that carry CRISPR-Cas (Palmer et al., 2010, 2012). This indicates that the CRISPR-Cas status of E. faecalis strains may contribute to ecological adaptation. In E. faecium CRISPR-Cas is only found in a subset of clade B strains, again highlighting the general lack of barriers to horizontal gene exchange in this species (Lebreton et al., 2013). Restriction and anti-restriction systems located on mobile elements or enterococcal chromosomes can also determine the flow of adaptive traits among populations of the same and/or different species (Clewell et al., 2014). Anti-RM systems include analogs of ArdA (alleviation of restriction of DNA) that are located on conjugative transposons (CTns) that are found widely spread in enterococci. ArdA proteins act against Type I restriction systems (detected in Tn916 and CTn6000) and other genes presumptively involved in methylation (CTn6000) (Clewell et al., 2014). Recently, a type IIS restriction-modification (R-M) system SfaNI was described in E. faecalis (Furmanek-Blaszk and Sektas, 2015).

Other strategies seem to have exerted positive as well as negative selective pressures on E. faecalis clones. E. faecalis strain V583 uses phage particles to establish and maintain dominance of its intestinal niche in the presence of closely related competing strains (Duerkop et al., 2012). Furthermore, five of the seven prophages in the same strain (phage01, phage03, phage04, phage05, and phage07) can be excised from the bacterial chromosome and four of them produced infective virions that may promote gene dissemination among isolates and increase pathogenicity (Matos et al., 2013; La Rosa et al., 2015). Conversely, Gaca and Gilmore recently demonstrated how the accretion of mobile genetic elements in E. faecalis V583, renders it unable to co-exist with native enterococci in healthy human fecal flora (Gaca and Gilmore, 2016). 


\section{CONCLUSION}

The ubiquitous nature of enterococci, the flexibility of their genomes and the widespread use of antibiotics in human and veterinary medicine, are important factors that drive the current emergence of E. faecium and E. faecalis as MDR nosocomial pathogens.

The population structure of E. faecium is characterized by a deep phylogenetic split that separates human commensal isolates (clade B) from farm animal and hospital isolates (clade A). It is tempting to speculate that the deep phylogenetic split in E. faecium is driven by anthropogenic influences since strains from farm animals (clade A2) and clinical isolates (clade A1), share a common feature as they both originate from environments where mammalian hosts are in close contact with each other and usage of antibiotics is high. The evolutionary trajectory of E. faecium, which has led to a clear clade structure, suggests that E. faecium is colonizing rugged fitness landscapes, in which characters of particular clones in clade A and B impose strong fitness differences. Under these circumstances, gene exchange between diverging populations is reduced over large genomic regions, as a collateral effect of strong divergent selection on genes involved in local adaptation. This mechanism was named divergence hitchhiking (DH) (Via, 2012). DH facilitates the divergence of genes linked to genomic regions that are most involved in local adaptation, and may explain the evolution of clones in populations with extensive gene flow. In E. faecium clade A, DH may have contributed to the fixation of ecologically important genomic traits, like antibiotic resistance or genes linked to pathogenicity. Indeed, using a neutral model incorporating microepidemics and migration, which mimics a situation where ecological factors may limit transmission between subpopulations, showed that E. faecium hospital isolates with extensive genotype relatedness markedly deviated from this neutral model compared with other common nosocomial bacteria like Staphylococcus aureus and Staphylococcus epidermidis, indicating that these hospital isolates represent a subpopulation adapted to the hospital environment (Numminen et al., 2016).

The E. faecalis population analyzed in the studies described above included human commensal, farm animal and clinical isolates. It is an open question why this anthropogenic divergence, as observed in E. faecium, is not seen in E. faecalis. An explanation for this may reside in differences in population size of both species. Indeed, E. faecalis seems to be more widespread and abundant in the intestines of cattle, pigs, dogs, horses and poultry (Devriese et al., 1987, 1991, 1992a,b, 1994). E. faecalis has also been more frequently isolated from wild mammals, reptiles, birds, insects, and wild plants than E. faecium (Mundt, 1963a,b; Martin and Mundt, 1972). Finally, in healthy humans E. faecalis is also more frequently found than E. faecium (Tannock and Cook, 2002). Moreover, it seems that E. faecalis clones are maintained longer in the gut than E. faecium clones (Ruiz-Garbajosa et al., 2009). The higher population density of E. faecalis relative to
E. faecium, in combination with its broader host-range, should provide E. faecalis with more opportunities for genetic exchange and diversification than E. faecium. High population densities also assure frequent transmission events, favoring gene flow among strains. This may act as a unifying force preventing the evolution of distinct clades in E. faecalis. Using the same neutral model described above for E. faecium, showed that the population structure of E. faecalis could be reflective of the evolutionary dynamics of a generalist organism which regularly experiences a high level of drift and gene flow between different host species (Numminen et al., 2016). Different strategies influence interactions of E. faecalis with populations of the same or of different species. A mechanism of substantial genetic exchange in E. faecalis has been postulated by Manson and co-workers, who described conjugative transfer of chromosomal fragments driven by integration of pheromone responsive conjugative plasmids carrying IS256 insertions and recombination across IS256 copies in the genome (Manson et al., 2010). The authors demonstrated that such an event could include transfer and recombination of up to $857 \mathrm{~kb}(\sim 25 \%$ of the genome $)$ and show that essentially every chromosomal location can be transferred by this mechanism. Other strategies may include phages, mobile genetic elements and the generation of polymicrobial biofilms (Weigel et al., 2007; La Rosa et al., 2015, 2016; Gaca and Gilmore, 2016).

High-level genetic connectivity of strains between different niches and hosts might favor dissemination of adaptive elements (e.g., virulence and resistance genes) that are acquired by E. faecalis populations in one niche (e.g., animals raised for food production) and finally end up being selected for in another environment (e.g., the hospital). In fact, the panmictic structure of $E$. faecalis favors its behavior as a collective evolutionary individual, which has promoted the generalist lifestyle of E. faecalis. The high level of genetic connectivity of E. faecalis strains in different niches, in combination with a relative small genome size, is in accordance with the 'Black Queen Hypothesis'. According to this hypothesis collective genes shared in a highly recombinogenic structure act as "common goods", and may favor the loss of genes in a particular niche in individual strains, provided they are not lost entirely from the community (Morris et al., 2012). While there is evidence in favor of this hypothesis, there is still a distinct lack of studies using WGS to describe the evolution, genetic diversity and population structure of E. faecalis and these are urgently needed to validate or falsify the current view of E. faecalis as a generalist.

In conclusion, E. faecium and E. faecalis are widely distributed among humans, animals and the environment. The social behavior of enterococci, which includes the accretion of plasmids, phages and CTns (Werner et al., 2013; Clewell et al., 2014), but also the ability to maintain microbial communities (Barnes et al., 2012; Paganelli et al., 2013), has allowed them to rapidly acquire antibiotic resistance genes and genetic elements that increase their ability to colonize and infect patients. E. faecium and E. faecalis differ in their population structure. E. faecium has clearly defined sub-populations, one of which contains 
the majority of strains that are currently causing nosocomial infections. In contrast, E. faecalis is a generalist, with a highly panmictic population where genes involved in patient colonization or virulence are widely spread across niches.

\section{AUTHOR CONTRIBUTIONS}

Most of the writing for this manuscript was done by AG, WS, and RW, with MR contributing analyses for both figures and TC, FB, and JC contributing concepts and text in sections 3 and 4. All authors have contributed to and revised the manuscript prior to submission. In our opinion, all authors meet the

\section{REFERENCES}

Aarestrup, F. M., Seyfarth, A. M., Emborg, H. D., Pedersen, K., Hendriksen, R. S., and Bager, F. (2001). Effect of abolishment of the use of antimicrobial agents for growth promotion on occurrence of antimicrobial resistance in fecal enterococci from food animals in Denmark. Antimicrob. Agents Chemother. 45, 2054-2059. doi: 10.1128/AAC.45.7.2054-2059.2001

Agudelo Higuita, N. I., and Huycke, M. M. (2014). "Enterococcal disease, epidemiology, and implications for treatment," in Enterococci: From Commensals to Leading Causes of Drug Resistant Infection, eds M. S. Gilmore, D. B. Clewell, Y. Ike, and N. Shankar (Boston: Massachusetts Eye and Ear Infirmary). Available at: http://www.ncbi.nlm.nih.gov/books/NBK190429/ [Accessed February 21, 2016].

Aksoy, D. Y., and Unal, S. (2008). New antimicrobial agents for the treatment of Gram-positive bacterial infections. Clin. Microbiol. Infect. Off. Publ. Eur. Soc. Clin. Microbiol. Infect. Dis. 14, 411-420. doi: 10.1111/j.1469-0691.2007.01933.x

Arias, C. A., and Murray, B. E. (2012). The rise of the Enterococcus: beyond vancomycin resistance. Nat. Rev. Microbiol. 10, 266-278. doi: 10.1038/nrmicro2761

Arias, C. A., Panesso, D., McGrath, D. M., Qin, X., Mojica, M. F., Miller, C., et al. (2011). Genetic basis for in vivo daptomycin resistance in enterococci. N. Engl. J. Med. 365, 892-900. doi: 10.1056/NEJMoa1011138

Arthur, M., Molinas, C., Depardieu, F., and Courvalin, P. (1993). Characterization of Tn1546, a Tn3-related transposon conferring glycopeptide resistance by synthesis of depsipeptide peptidoglycan precursors in Enterococcus faecium BM4147. J. Bacteriol. 175, 117-127.

Aslangul, E., Massias, L., Meulemans, A., Chau, F., Andremont, A., Courvalin, P., et al. (2006). Acquired gentamicin resistance by permeability impairment in Enterococcus faecalis. Antimicrob. Agents Chemother. 50, 3615-3621. doi: 10.1128/AAC.00390-06

Bager, F., Madsen, M., Christensen, J., and Aarestrup, F. M. (1997). Avoparcin used as a growth promoter is associated with the occurrence of vancomycinresistant Enterococcus faecium on Danish poultry and pig farms. Prev. Vet. Med. 31, 95-112. doi: 10.1016/S0167-5877(96)01119-1

Baquero, F. (2004). From pieces to patterns: evolutionary engineering in bacterial pathogens. Nat. Rev. Microbiol. 2, 510-518. doi: 10.1038/nrmicro909

Barber, K. E., Smith, J. R., Raut, A., and Rybak, M. J. (2016). Evaluation of tedizolid against Staphylococcus aureus and enterococci with reduced susceptibility to vancomycin, daptomycin or linezolid. J. Antimicrob. Chemother. 71, 152-155. doi: $10.1093 / \mathrm{jac} / \mathrm{dkv} 302$

Barnes, A. M. T., Ballering, K. S., Leibman, R. S., Wells, C. L., and Dunny, G. M. (2012). Enterococcus faecalis produces abundant extracellular structures containing DNA in the absence of cell lysis during early biofilm formation. mbio 3:e193. doi: 10.1128/mBio.00193-112

Beabout, K., Hammerstrom, T. G., Perez, A. M., Magalhães, B. F., Prater, A. G., Clements, T. P., et al. (2015). The ribosomal S10 protein is a general target for decreased tigecycline susceptibility. Antimicrob. Agents Chemother. 59, 5561-5566. doi: 10.1128/AAC.00547-15 requirement of authorship as outlined in the Frontiers author guidelines.

\section{ACKNOWLEDGMENTS}

WS is funded through a NWO-Vidi grant (917.13.357). TC and FB are supported by grants PI12-01581 and PI15-01307 from the ISCIII-Ministry of Economy and Competitiveness of Spain (to TC), S2010/BMD2414 from the Regional Government of Madrid (to FB) and the CIBERESP Network for Biomedical Research in Epidemiology and Public Health (Instituto Carlos III, Spanish Ministry of Science and Innovation, reference number CB06/02/0053).

Bender, J. K., Kalmbach, A., Fleige, C., Klare, I., Fuchs, S., and Werner, G. (2016). Population structure and acquisition of the vanB resistance determinant in German clinical isolates of Enterococcus faecium ST192. Sci. Rep. 6:21847. doi: 10.1038/srep21847

Bourdon, N., Fines-Guyon, M., Thiolet, J.-M., Maugat, S., Coignard, B., Leclercq, R., et al. (2011). Changing trends in vancomycin-resistant enterococci in French hospitals, 2001-08. J. Antimicrob. Chemother. 66, 713-721. doi: $10.1093 / \mathrm{jac} / \mathrm{dkq} 524$

Boyd, D. A., Willey, B. M., Fawcett, D., Gillani, N., and Mulvey, M. R. (2008). Molecular characterization of Enterococcus faecalis N06-0364 with low-level vancomycin resistance harboring a novel D-Ala-D-Ser gene cluster, vanL. Antimicrob. Agents Chemother. 52, 2667-2672. doi: 10.1128/AAC.01516-07

Brandl, K., Plitas, G., Mihu, C. N., Ubeda, C., Jia, T., Fleisher, M., et al. (2008). Vancomycin-resistant enterococci exploit antibiotic-induced innate immune deficits. Nature 455, 804-807. doi: 10.1038/nature07250

Brodrick, H. J., Raven, K. E., Harrison, E. M., Blane, B., Reuter, S., Török, M. E., et al. (2016). Whole-genome sequencing reveals transmission of vancomycinresistant Enterococcus faecium in a healthcare network. Genome Med. 8:4. doi: 10.1186/s13073-015-0259-7

Brötz-Oesterhelt, H., Beyer, D., Kroll, H.-P., Endermann, R., Ladel, C., Schroeder, W., et al. (2005). Dysregulation of bacterial proteolytic machinery by a new class of antibiotics. Nat. Med. 11, 1082-1087. doi: 10.1038/ nm1306

Byappanahalli, M. N., Nevers, M. B., Korajkic, A., Staley, Z. R., and Harwood, V. J. (2012). Enterococci in the environment. Microbiol. Mol. Biol. Rev. 76, 685-706. doi: 10.1128/MMBR.00023-12

Cai, J., Wang, Y., Schwarz, S., Lv, H., Li, Y., Liao, K., et al. (2015). Enterococcal isolates carrying the novel oxazolidinone resistance gene optrA from hospitals in Zhejiang, Guangdong, and Henan, China, 2010-2014. Clin. Microbiol. Infect. Off. Publ. Eur. Soc. Clin. Microbiol. Infect. Dis. 21, e1-e4. doi: 10.1016/j.cmi.2015.08.007

Cattoir, V., and Giard, J.-C. (2014). Antibiotic resistance in Enterococcus faecium clinical isolates. Expert Rev. Anti Infect. Ther. 12, 239-248. doi: 10.1586/14787210.2014.870886

Cattoir, V., Isnard, C., Cosquer, T., Odhiambo, A., Bucquet, F., Guérin, F., et al. (2015). Genomic analysis of reduced susceptibility to tigecycline in Enterococcus faecium. Antimicrob. Agents Chemother. 59, 239-244. doi: 10.1128/AAC.04174-14

Chen, C., Sun, J., Guo, Y., Lin, D., Guo, Q., Hu, F., et al. (2015). High Prevalence of vanM in Vancomycin-Resistant Enterococcus faecium Isolates from Shanghai, China. Antimicrob. Agents Chemother. 59, 7795-7798. doi: 10.1128/AAC.01732-15

Chen, H., Wu, W., Ni, M., Liu, Y., Zhang, J., Xia, F., et al. (2013). Linezolid-resistant clinical isolates of enterococci and Staphylococcus cohnii from a multicentre study in China: molecular epidemiology and resistance mechanisms. Int. J. Antimicrob. Agents 42, 317-321. doi: 10.1016/j.ijantimicag.2013.06.008

Chow, J. W. (2000). Aminoglycoside resistance in enterococci. Clin. Infect. Dis. Off. Publ. Infect. Dis. Soc. Am. 31, 586-589. doi: 10.1086/313949 
Clewell, D. B., Weaver, K. E., Dunny, G. M., Coque, T. M., Francia, M. V., and Hayes, F. (2014). "Extrachromosomal and mobile elements in enterococci: transmission, maintenance, and epidemiology," in Enterococci: From Commensals to Leading Causes of Drug Resistant Infection, eds M. S. Gilmore, D. B. Clewell, Y. Ike, and N. Shankar (Boston: Massachusetts Eye and Ear Infirmary). Available at: http://www.ncbi.nlm.nih.gov/books/NBK190430/ [Accessed March 19, 2016].

Colca, J. R., McDonald, W. G., Waldon, D. J., Thomasco, L. M., Gadwood, R. C., Lund, E. T., et al. (2003). Cross-linking in the living cell locates the site of action of oxazolidinone antibiotics. J. Biol. Chem. 278, 21972-21979. doi: 10.1074/jbc.M302109200

Coombs, G. W., Pearson, J. C., Daley, D. A., Le, T., Robinson, O. J., Gottlieb, T., et al. (2014). Molecular epidemiology of enterococcal bacteremia in Australia. J. Clin. Microbiol. 52, 897-905. doi: 10.1128/JCM.03286-13

Corander, J., Connor, T. R., O’Dwyer, C. A., Kroll, J. S., and Hanage, W. P. (2012). Population structure in the Neisseria, and the biological significance of fuzzy species. J. R. Soc. Interface R. Soc. 9, 1208-1215. doi: 10.1098/rsif.2011.0601

Cordina, C., Hill, R., Deshpande, A., Hood, J., and Inkster, T. (2012). Tigecyclineresistant Enterococcus faecalis associated with omeprazole use in a surgical patient. J. Antimicrob. Chemother. 67, 1806-1807. doi: 10.1093/jac/dks122

Costa, Y., Galimand, M., Leclercq, R., Duval, J., and Courvalin, P. (1993). Characterization of the chromosomal aac(6')-Ii gene specific for Enterococcus faecium. Antimicrob. Agents Chemother. 37, 1896-1903. doi: 10.1128/AAC.37.9.1896

Courvalin, P. (2006). Vancomycin resistance in gram-positive cocci. Clin. Infect. Dis. Off. Publ. Infect. Dis. Soc. Am. 42(Suppl. 1), S25-S34. doi: 10.1086/491711

Creti, R., Imperi, M., Bertuccini, L., Fabretti, F., Orefici, G., Di Rosa, R., et al. (2004). Survey for virulence determinants among Enterococcus faecalis isolated from different sources. J. Med. Microbiol. 53, 13-20. doi: 10.1099/jmm.0. 05353-0

Crotty, M. P., Krekel, T., Burnham, C. A., and Ritchie, D. J. (2016). New grampositive agents: the next generation of oxazolidinones and lipoglycopeptides. J. Clin. Microbiol. doi: 10.1128/JCM.03395-15 [Epub ahead of print].

Dahl, K. H., Lundblad, E. W., Rokenes, T. P., Olsvik, O., and Sundsfjord, A. (2000). Genetic linkage of the vanB2 gene cluster to Tn5382 in vancomycin-resistant enterococci and characterization of two novel insertion sequences. Microbiol. Read. Engl. 146(Pt 6), 1469-1479. doi: 10.1099/00221287-146-6-1469

Davlieva, M., Zhang, W., Arias, C. A., and Shamoo, Y. (2013). Biochemical characterization of cardiolipin synthase mutations associated with daptomycin resistance in enterococci. Antimicrob. Agents Chemother. 57, 289-296. doi: 10.1128/AAC.01743-12

de Been, M., Pinholt, M., Top, J., Bletz, S., Mellmann, A., van Schaik, W., et al. (2015). A core genome MLST scheme for high-resolution typing of Enterococcus faecium. J. Clin. Microbiol. 53, 3788-3797. doi: 10.1128/JCM.01946-15

de Been, M., van Schaik, W., Cheng, L., Corander, J., and Willems, R. J. (2013). Recent recombination events in the core genome are associated with adaptive evolution in Enterococcus faecium. Genome Biol. Evol. 5, 1524-1535. doi: 10.1093/gbe/evt111

de Kraker, M. E. A., Jarlier, V., Monen, J. C. M., Heuer, O. E., van de Sande, N., and Grundmann, H. (2013). The changing epidemiology of bacteraemias in Europe: trends from the European Antimicrobial Resistance Surveillance System. Clin. Microbiol. Infect. Off. Publ. Eur. Soc. Clin. Microbiol. Infect. Dis. 19, 860-868. doi: 10.1111/1469-0691.12028

De Vecchi, E., Sitia, S., Romanò, C. L., Ricci, C., Mattina, R., and Drago, L. (2013). Aetiology and antibiotic resistance patterns of urinary tract infections in the elderly: a 6-month study. J. Med. Microbiol. 62, 859-863. doi: 10.1099/jmm.0.056945-0

Devriese, L. A., Colque, J. I. C., De Herdt, P., and Haesebrouck, F. (1992a). Identification and composition of the tonsillar and anal enterococcal and streptococcal flora of dogs and cats. J. Appl. Microbiol. 73, 421-425. doi: 10.1111/j.1365-2672.1992.tb04998.x

Devriese, L. A., Hommez, J., Pot, B., and Haesebrouck, F. (1994). Identification and composition of the streptococcal and enterococcal flora of tonsils, intestines and faeces of pigs. J. Appl. Bacteriol. 77, 31-36. doi: 10.1111/j.13652672.1994.tb03040.x
Devriese, L. A., Hommez, J., Wijfels, R., and Haesebrouck, F. (1991). Composition of the enterococcal and streptococcal intestinal flora of poultry. J. Appl. Bacteriol. 71, 46-50. doi: 10.1111/j.1365-2672.1991.tb04585.x

Devriese, L. A., Ieven, M., Goossens, H., Vandamme, P., Pot, B., Hommez, J., et al. (1996). Presence of vancomycin-resistant enterococci in farm and pet animals. Antimicrob. Agents Chemother. 40, 2285-2287.

Devriese, L. A., Kerckhove, A. V. D., Kilpper-Bälz, R., and Schleifer, K. H. (1987). Characterization and Identification of Enterococcus Species Isolated from the Intestines of Animals. Int. J. Syst. Bacteriol. 37, 257-259. doi: 10.1099/0020771337-3-257

Devriese, L. A., Laurier, L., De Herdt, P., and Haesebrouck, F. (1992b). Enterococcal and streptococcal species isolated from faeces of calves, young cattle and dairy cows. J. Appl. Bacteriol. 72, 29-31. doi: 10.1111/j.1365-2672.1992. tb05182.x

Diaz, L., Kiratisin, P., Mendes, R. E., Panesso, D., Singh, K. V., and Arias, C. A. (2012). Transferable plasmid-mediated resistance to linezolid due to cfr in a human clinical isolate of Enterococcus faecalis. Antimicrob. Agents Chemother. 56, 3917-3922. doi: 10.1128/AAC.00419-12

Didelot, X., and Falush, D. (2007). Inference of bacterial microevolution using multilocus sequence data. Genetics 175, 1251-1266. doi: 10.1534/genetics.106.063305

Domingo, M.-C., Huletsky, A., Giroux, R., Picard, F. J., and Bergeron, M. G. (2007). vanD and vanG-Like Gene Clusters in a Ruminococcus Species Isolated from Human Bowel Flora. Antimicrob. Agents Chemother. 51, 4111-4117. doi: 10.1128/AAC.00584-07

Donskey, C. J., Chowdhry, T. K., Hecker, M. T., Hoyen, C. K., Hanrahan, J. A., Hujer, A. M., et al. (2000). Effect of antibiotic therapy on the density of vancomycin-resistant enterococci in the stool of colonized patients. N. Engl. J. Med. 343, 1925-1932. doi: 10.1056/NEJM200012283 432604

Duerkop, B. A., Clements, C. V., Rollins, D., Rodrigues, J. L. M., and Hooper, L. V. (2012). A composite bacteriophage alters colonization by an intestinal commensal bacterium. Proc. Natl. Acad. Sci. U.S.A. 109, 17621-17626. doi: 10.1073/pnas. 1206136109

Eaton, T. J., and Gasson, M. J. (2001). Molecular screening of Enterococcus virulence determinants and potential for genetic exchange between food and medical isolates. Appl. Environ. Microbiol. 67, 1628-1635. doi: 10.1128/AEM.67.4.1628-1635.2001

Edelsberg, J., Weycker, D., Barron, R., Li, X., Wu, H., Oster, G., et al. (2014). Prevalence of antibiotic resistance in US hospitals. Diagn. Microbiol. Infect. Dis. 78, 255-262. doi: 10.1016/j.diagmicrobio.2013.11.011

Feil, E. J., Li, B. C., Aanensen, D. M., Hanage, W. P., and Spratt, B. G. (2004). eBURST: inferring patterns of evolutionary descent among clusters of related bacterial genotypes from multilocus sequence typing data. J. Bacteriol. 186, 1518-1530. doi: 10.1128/JB.186.5.1518-1530.2004

Fernández-Guerrero, M. L., Herrero, L., Bellver, M., Gadea, I., Roblas, R. F., and de Górgolas, M. (2002). Nosocomial enterococcal endocarditis: a serious hazard for hospitalized patients with enterococcal bacteraemia. J. Intern. Med. 252, 510-515. doi: 10.1046/j.1365-2796.2002.01061.x

Fiedler, S., Bender, J. K., Klare, I., Halbedel, S., Grohmann, E., Szewzyk, U., et al. (2015). Tigecycline resistance in clinical isolates of Enterococcus faecium is mediated by an upregulation of plasmid-encoded tetracycline determinants tet(L) and tet(M). J. Antimicrob. Chemother. 71, 871-881. doi: 10.1093/jac/dkv420

Francisco, A. P., Bugalho, M., Ramirez, M., and Carriço, J. A. (2009). Global optimal eBURST analysis of multilocus typing data using a graphic matroid approach. BMC Bioinformatics 10:152. doi: 10.1186/1471-2105-10-152

Freitas, A. R., Novais, C., Correia, R., Monteiro, M., Coque, T. M., and Peixe, L. (2011). Non-susceptibility to tigecycline in enterococci from hospitalised patients, food products and community sources. Int. J. Antimicrob. Agents 38, 174-176. doi: 10.1016/j.ijantimicag.2011.04.014

Freitas, A. R., Novais, C., Ruiz-Garbajosa, P., Coque, T. M., and Peixe, L. (2009). Clonal expansion within clonal complex 2 and spread of vancomycinresistant plasmids among different genetic lineages of Enterococcus faecalis from Portugal. J. Antimicrob. Chemother. 63, 1104-1111. doi: 10.1093/jac/ dkp103 
Furmanek-Blaszk, B., and Sektas, M. (2015). The SfaNI restriction-modification system from Enterococcus faecalis NEB215 is located on a putative mobile genetic element. FEMS Microbiol. Lett. 362:fnv028. doi: 10.1093/femsle/fnv028

Gaca, A. O., and Gilmore, M. S. (2016). Killing of VRE Enterococcus faecalis by commensal strains: evidence for evolution and accumulation of mobile elements in the absence of competition. Gut Microbes 7, 90-96. doi: 10.1080/19490976.2015.1127482

Galimand, M., Schmitt, E., Panvert, M., Desmolaize, B., Douthwaite, S., Mechulam, Y., et al. (2011). Intrinsic resistance to aminoglycosides in Enterococcus faecium is conferred by the 16S rRNA m5C1404-specific methyltransferase EfmM. RNA N. Y. N 17, 251-262. doi: 10.1261/rna.2233511

Galloway-Peña, J., Roh, J. H., Latorre, M., Qin, X., and Murray, B. E. (2012). Genomic and SNP analyses demonstrate a distant separation of the hospital and community-associated clades of Enterococcus faecium. PLoS ONE 7:e30187. doi: 10.1371/journal.pone.0030187

Galloway-Peña, J. R., Nallapareddy, S. R., Arias, C. A., Eliopoulos, G. M., and Murray, B. E. (2009). Analysis of clonality and antibiotic resistance among early clinical isolates of Enterococcus faecium in the United States. J. Infect. Dis. 200, 1566-1573. doi: 10.1086/644790

Galloway-Peña, J. R., Rice, L. B., and Murray, B. E. (2011). Analysis of PBP5 of early U.S. isolates of Enterococcus faecium: sequence variation alone does not explain increasing ampicillin resistance over time. Antimicrob. Agents Chemother. 55, 3272-3277. doi: 10.1128/AAC.00099-11

Gastmeier, P., Schröder, C., Behnke, M., Meyer, E., and Geffers, C. (2014). Dramatic increase in vancomycin-resistant enterococci in Germany. J. Antimicrob. Chemother. 69, 1660-1664. doi: 10.1093/jac/dku035

Gilmore, M. S., Lebreton, F., and van Schaik, W. (2013). Genomic transition of enterococci from gut commensals to leading causes of multidrug-resistant hospital infection in the antibiotic era. Curr. Opin. Microbiol. 16, 10-16. doi: 10.1016/j.mib.2013.01.006

Grayson, M. L., Eliopoulos, G. M., Wennersten, C. B., Ruoff, K. L., De Girolami, P. C., Ferraro, M. J., et al. (1991). Increasing resistance to betalactam antibiotics among clinical isolates of Enterococcus faecium: a 22 -year review at one institution. Antimicrob. Agents Chemother. 35, 2180-2184. doi: 10.1128/AAC.35.11.2180

Guardabassi, L., Perichon, B., van Heijenoort, J., Blanot, D., and Courvalin, P. (2005). Glycopeptide resistance vana operons in paenibacillus strains isolated from soil. Antimicrob. Agents Chemother. 49, 4227-4233. doi: 10.1128/AAC.49.10.4227-4233.2005

Hanrahan, J., Hoyen, C., and Rice, L. B. (2000). Geographic distribution of a large mobile element that transfers ampicillin and vancomycin resistance between Enterococcus faecium strains. Antimicrob. Agents Chemother. 44, 1349-1351. doi: 10.1128/AAC.44.5.1349-1351.2000

Hegstad, K., Mikalsen, T., Coque, T. M., Werner, G., and Sundsfjord, A. (2010). Mobile genetic elements and their contribution to the emergence of antimicrobial resistant Enterococcus faecalis and Enterococcus faecium. Clin. Microbiol. Infect. Off. Publ. Eur. Soc. Clin. Microbiol. Infect. Dis. 16, 541-554. doi: 10.1111/j.1469-0691.2010.03226.x

Heikens, E., Bonten, M. J., and Willems, R. J. (2007). Enterococcal Surface Protein Esp Is Important for Biofilm Formation of Enterococcus faecium E1162. J. Bacteriol. 189, 8233-8240. doi: 10.1128/JB.01205-07

Heikens, E., Singh, K. V., Jacques-Palaz, K. D., van Luit-Asbroek, M., Oostdijk, E. A. N., Bonten, M. J. M., et al. (2011). Contribution of the enterococcal surface protein Esp to pathogenesis of Enterococcus faecium endocarditis. Microbes Infect. Inst. Pasteur 13, 1185-1190. doi: 10.1016/j.micinf.2011. 08.006

Heikens, E., van Schaik, W., Leavis, H. L., Bonten, M. J., and Willems, R. J. (2008). Identification of a novel genomic island specific to hospital-acquired clonal complex 17 Enterococcus faecium isolates. Appl. Environ. Microbiol. 74, 7094-7097. doi: 10.1128/AEM.01378-08

Hendrickx, A. P., Willems, R. J., Bonten, M. J., and van Schaik, W. (2009). LPxTG surface proteins of enterococci. Trends Microbiol. 17, 423-430. doi: 10.1016/j.tim.2009.06.004

Hendrickx, A. P. A., van Schaik, W., and Willems, R. J. L. (2013). The cell wall architecture of Enterococcus faecium: from resistance to pathogenesis. Fut. Microbiol. 8, 993-1010. doi: 10.2217/fmb.13.66

Hoban, D. J., Reinert, R. R., Bouchillon, S. K., and Dowzicky, M. J. (2015). Global in vitro activity of tigecycline and comparator agents: tigecycline Evaluation and Surveillance Trial 2004-2013. Ann. Clin. Microbiol. Antimicrob. 14:27. doi: 10.1186/s12941-015-0085-1

Homan, W. L., Tribe, D., Poznanski, S., Li, M., Hogg, G., Spalburg, E., et al. (2002). Multilocus sequence typing scheme for Enterococcus faecium. J. Clin. Microbiol. 40, 1963-1971. doi: 10.1128/JCM.40.6.1963-1971.2002

Horvath, P., and Barrangou, R. (2010). CRISPR/Cas, the immune system of bacteria and archaea. Science 327, 167-170. doi: 10.1126/science.1179555

Howden, B. P., Holt, K. E., Lam, M. M. C., Seemann, T., Ballard, S., Coombs, G. W., et al. (2013). Genomic insights to control the emergence of vancomycinresistant enterococci. mBio 4, e412-e413. doi: 10.1128/mBio.00412-13

Humphries, R. M., Pollett, S., and Sakoulas, G. (2013). A current perspective on daptomycin for the clinical microbiologist. Clin. Microbiol. Rev. 26, 759-780. doi: 10.1128/CMR.00030-13

Jensen, L. B., Ahrens, P., Dons, L., Jones, R. N., Hammerum, A. M., and Aarestrup, F. M. (1998). Molecular analysis of Tn1546 in Enterococcus faecium isolated from animals and humans. J. Clin. Microbiol. 36, 437-442.

Jones, R. N., Ross, J. E., Castanheira, M., and Mendes, R. E. (2008). United States resistance surveillance results for linezolid (LEADER Program for 2007). Diagn. Microbiol. Infect. Dis. 62, 416-426. doi: 10.1016/j.diagmicrobio.2008. 10.010

Jones, R. N., Sader, H. S., and Flamm, R. K. (2013). Update of dalbavancin spectrum and potency in the USA: report from the SENTRY Antimicrobial Surveillance Program (2011). Diagn. Microbiol. Infect. Dis. 75, 304-307. doi: 10.1016/j.diagmicrobio.2012.11.024

Jordan, S., Junker, A., Helmann, J. D., and Mascher, T. (2006). Regulation of LiaRS-dependent gene expression in Bacillus subtilis: identification of inhibitor proteins, regulator binding sites, and target genes of a conserved cell envelope stress-sensing two-component system. J. Bacteriol. 188, 5153-5166. doi: 10.1128/JB.00310-06

Kamboj, M., Blair, R., Bell, N., Sun, J., Eagan, J., and Sepkowitz, K. (2014). What is the source of bloodstream infection due to vancomycin-resistant enterococci in persons with mucosal barrier injury? Infect. Control Hosp. Epidemiol. 35, 99-101. doi: 10.1086/674406

Karlowsky, J. A., Nichol, K., and Zhanel, G. G. (2015). Telavancin: mechanisms of action, in vitro activity, and mechanisms of resistance. Clin. Infect. Dis. Off. Publ. Infect. Dis. Soc. Am. 61(Suppl. 2), S58-S68. doi: 10.1093/cid/civ534

Kawalec, M., Pietras, Z., Daniłowicz, E., Jakubczak, A., Gniadkowski, M., Hryniewicz, W., et al. (2007). Clonal structure of Enterococcus faecalis isolated from Polish hospitals: characterization of epidemic clones. J. Clin. Microbiol. 45, 147-153. doi: 10.1128/JCM.01704-06

Kelesidis, T., Tewhey, R., and Humphries, R. M. (2013). Evolution of high-level daptomycin resistance in Enterococcus faecium during daptomycin therapy is associated with limited mutations in the bacterial genome. J. Antimicrob. Chemother. 68, 1926-1928. doi: 10.1093/jac/dkt117

Kim, E. B., and Marco, M. L. (2013). Non-clinical and clinical Enterococcus faecium but not Enterococcus faecalis have distinct structural and functional genomic features. Appl. Environ. Microbiol. 80, 154-165.

Klare, I., Badstübner, D., Konstabel, C., Böhme, G., Claus, H., and Witte, W. (1999). Decreased incidence of VanA-type vancomycin-resistant enterococci isolated from poultry meat and from fecal samples of humans in the community after discontinuation of avoparcin usage in animal husbandry. Microb. Drug Resist. Larchmt. N 5, 45-52. doi: 10.1089/mdr.1999.5.45

Klare, I., Heier, H., Claus, H., Böhme, G., Marin, S., Seltmann, G., et al. (1995). Enterococcus faecium strains with vanA-mediated high-level glycopeptide resistance isolated from animal foodstuffs and fecal samples of humans in the community. Microb. Drug Resist. Larchmt. $N$ 1, 265-272. doi: 10.1089/mdr.1995.1.265

Kuch, A., Willems, R. J. L., Werner, G., Coque, T. M., Hammerum, A. M., Sundsfjord, A., et al. (2012). Insight into antimicrobial susceptibility and population structure of contemporary human Enterococcus faecalis isolates from Europe. J. Antimicrob. Chemother. 67, 551-558. doi: 10.1093/jac/ $\mathrm{dkr} 544$

La Rosa, S. L., Montealegre, M. C., Singh, K. V., and Murray, B. E. (2016). Enterococcus faecalis Ebp Pili are important for cell-cell aggregation and intraspecies gene transfer. Microbiol. Read. Engl. 162, 798-802. doi: 10.1099/mic.0.000276

La Rosa, S. L., Snipen, L.-G., Murray, B. E., Willems, R. J. L., Gilmore, M. S., Diep, D. B., et al. (2015). A genomic virulence reference map of Enterococcus faecalis 
reveals an important contribution of phage03-like elements in nosocomial genetic lineages to pathogenicity in a Caenorhabditis elegans infection model. Infect. Immun. 83, 2156-2167. doi: 10.1128/IAI.02801-14

Leavis, H., Top, J., Shankar, N., Borgen, K., Bonten, M., Van Embden, J., et al. (2004). a novel putative enterococcal pathogenicity island linked to the esp virulence gene of Enterococcus faecium and associated with epidemicity. J. Bacteriol. 186, 672-682. doi: 10.1128/JB.186.3.672682.2004

Leavis, H. L., Willems, R. J., Top, J., Spalburg, E., Mascini, E. M., Fluit, A. C., et al. (2003). Epidemic and nonepidemic multidrug-resistant Enterococcus faecium. Emerg. Infect. Dis. 9, 1108-1115. doi: 10.3201/eid0909.020383

Lebreton, F., Depardieu, F., Bourdon, N., Fines-Guyon, M., Berger, P., Camiade, S., et al. (2011). D-Ala-d-Ser VanN-type transferable vancomycin resistance in Enterococcus faecium. Antimicrob. Agents Chemother. 55, 4606-4612. doi: 10.1128/AAC.00714-11

Lebreton, F., van Schaik, W., McGuire, A. M., Godfrey, P., Griggs, A., Mazumdar, V., et al. (2013). Emergence of epidemic multidrug-resistant Enterococcus faecium from animal and commensal strains. mBio 4:e534. doi: 10.1128/mBio.00534-13

Leclercq, R., Derlot, E., Duval, J., and Courvalin, P. (1988). Plasmidmediated resistance to vancomycin and teicoplanin in Enterococcus faecium. N. Engl. J. Med. 319, 157-161. doi: 10.1056/NEJM1988072131 90307

Leclercq, R., Oberlé, K., Galopin, S., Cattoir, V., Budzinski, H., and Petit, F. (2013). Changes in enterococcal populations and related antibiotic resistance along a medical center-wastewater treatment plant-river continuum. Appl. Environ. Microbiol. 79, 2428-2434. doi: 10.1128/AEM. 03586-12

Leendertse, M., Heikens, E., Wijnands, L. M., van Luit-Asbroek, M., Teske, G. J., Roelofs, J. J., et al. (2009). Enterococcal surface protein transiently aggravates Enterococcus faecium-induced urinary tract infection in mice. J. Infect. Dis. 200, 1162-1165. doi: 10.1086/605609

Lellek, H., Franke, G. C., Ruckert, C., Wolters, M., Wolschke, C., Christner, M., et al. (2015). Emergence of daptomycin non-susceptibility in colonizing vancomycin-resistant Enterococcus faecium isolates during daptomycin therapy. Int. J. Med. Microbiol. IJMM 305, 902-909. doi: 10.1016/j.ijmm.2015.09.005

Ling, L. L., Schneider, T., Peoples, A. J., Spoering, A. L., Engels, I., Conlon, B. P., et al. (2015). A new antibiotic kills pathogens without detectable resistance. Nature 517, 455-459. doi: 10.1038/nature 14098

Lübbert, C., Rodloff, A. C., and Hamed, K. (2015). Real-world treatment of enterococcal infections with daptomycin: insights from a large european registry (EU-CORE). Infect. Dis. Ther. 4, 259-271. doi: 10.1007/s40121-0150072-z

Manson, J. M., Hancock, L. E., and Gilmore, M. S. (2010). Mechanism of chromosomal transfer of Enterococcus faecalis pathogenicity island, capsule, antimicrobial resistance, and other traits. Proc. Natl. Acad. Sci. U.S.A. 107, 12269-12274. doi: 10.1073/pnas.1000139107

Martin, J. D., and Mundt, J. O. (1972). Enterococci in insects. Appl. Microbiol. 24, 575-580.

Matos, R. C., Lapaque, N., Rigottier-Gois, L., Debarbieux, L., Meylheuc, T., Gonzalez-Zorn, B., et al. (2013). Enterococcus faecalis prophage dynamics and contributions to pathogenic traits. PLoS Genet. 9:e1003539. doi: 10.1371/journal.pgen.1003539

McBride, S. M., Fischetti, V. A., Leblanc, D. J., Moellering, R. C. Jr., and Gilmore, M. S. (2007). Genetic diversity among Enterococcus faecalis. PLoS ONE 2:e582. doi: 10.1371/journal.pone.0000582

Miller, W. R., Munita, J. M., and Arias, C. A. (2014). Mechanisms of antibiotic resistance in enterococci. Expert Rev. Anti Infect. Ther. 12, 1221-1236. doi: 10.1586/14787210.2014.956092

Montealegre, M. C., Singh, K. V., and Murray, B. E. (2015). Gastrointestinal tract colonization dynamics by different Enterococcus faecium clades. J. Infect. Dis. doi: 10.1093/infdis/jiv597 [Epub ahead of print].

Montero, C. I., Stock, F., and Murray, P. R. (2008). Mechanisms of resistance to daptomycin in Enterococcus faecium. Antimicrob. Agents Chemother. 52, 1167-1170. doi: 10.1128/AAC.00774-07
Morris, J. J., Lenski, R. E., and Zinser, E. R. (2012). The Black Queen Hypothesis: evolution of dependencies through adaptive gene loss. mBio 3:e00036. doi: 10.1128/mBio.00036-12

Morrison, D., Woodford, N., Barrett, S. P., Sisson, P., and Cookson, B. D. (1999). DNA banding pattern polymorphism in vancomycin-resistant Enterococcus faecium and criteria for defining strains. J. Clin. Microbiol. 37, 1084-1091.

Mundt, J. O. (1963a). Occurrence of enterococci in animals in a wild environment. Appl. Microbiol. 11, 136-140.

Mundt, J. O. (1963b). Occurrence of enterococci on plants in a wild environment. Appl. Microbiol. 11, 141-144.

Munita, J. M., Mishra, N. N., Alvarez, D., Tran, T. T., Diaz, L., Panesso, D., et al. (2014). Failure of high-dose daptomycin for bacteremia caused by daptomycinsusceptible Enterococcus faecium harboring LiaSR substitutions. Clin. Infect. Dis. Off. Publ. Infect. Dis. Soc. Am. 59, 1277-1280. doi: 10.1093/cid/ciu642

Munita, J. M., Panesso, D., Diaz, L., Tran, T. T., Reyes, J., Wanger, A., et al. (2012). Correlation between Mutations in liaFSR of Enterococcus faecium and MIC of daptomycin: revisiting daptomycin breakpoints. Antimicrob. Agents Chemother. 56, 4354-4359. doi: 10.1128/AAC.00509-12

National Nosocomial Infections Surveillance System (2004). National Nosocomial Infections Surveillance (NNIS) System Report, data summary from January 1992 through June 2004, issued October 2004. Am. J. Infect. Control 32, 470-485. doi: 10.1016/S0196655304005425

Neelakanta, A., Sharma, S., Kesani, V. P., Salim, M., Pervaiz, A., Aftab, N., et al. (2015). Impact of changes in the NHSN catheter-associated urinary tract infection (CAUTI) surveillance criteria on the frequency and epidemiology of CAUTI in intensive care units (ICUs). Infect. Control Hosp. Epidemiol. 36, 346-349. doi: 10.1017/ice.2014.67

Niebel, M., Quick, J., Prieto, A. M. G., Hill, R. L. R., Pike, R., Huber, D., et al. (2015). Deletions in a ribosomal protein-coding gene are associated with tigecycline resistance in Enterococcus faecium. Int. J. Antimicrob. Agents 46, 572-575. doi: 10.1016/j.ijantimicag.2015.07.009

Numminen, E., Gutmann, M., Shubin, M., Marttinen, P., Méric, G., van Schaik, W., et al. (2016). The impact of host metapopulation structure on the population genetics of colonizing bacteria. J. Theor. Biol. 396, 53-62. doi: 10.1016/j.jtbi.2016.02.019

Paganelli, F. L., Huebner, J., Singh, K. V., Zhang, X., van Schaik, W., Wobser, D., et al. (2016). Genome-wide screening identifies PTS permease BepA to be involved in Enterococcus faecium endocarditis and biofilm formation. J. Infect. Dis. doi: 10.1093/infdis/jiw108 [Epub ahead of print].

Paganelli, F. L., Willems, R. J. L., Jansen, P., Hendrickx, A., Zhang, X., Bonten, M. J. M., et al. (2013). Enterococcus faecium biofilm formation: identification of major autolysin AtlAEfm, associated Acm surface localization, and atlaefm-independent extracellular DNA release. mBio 4:e154. doi: 10.1128/mBio.00154-13

Palmer, K. L., Daniel, A., Hardy, C., Silverman, J., and Gilmore, M. S. (2011). Genetic basis for daptomycin resistance in enterococci. Antimicrob. Agents Chemother. 55, 3345-3356. doi: 10.1128/AAC.00207-11

Palmer, K. L., Godfrey, P., Griggs, A., Kos, V. N., Zucker, J., Desjardins, C., et al. (2012). Comparative genomics of enterococci: variation in Enterococcus faecalis, clade structure in E. faecium, and defining characteristics of E. gallinarum and E. casseliflavus. mBio 3:e318. doi: 10.1128/mBio.00318-11

Palmer, K. L., Kos, V. N., and Gilmore, M. S. (2010). Horizontal gene transfer and the genomics of enterococcal antibiotic resistance. Curr. Opin. Microbiol. 13, 632-639. doi: 10.1016/j.mib.2010.08.004

Parte, A. C. (2014). LPSN-list of prokaryotic names with standing in nomenclature. Nucleic Acids Res. 42, D613-D616. doi: 10.1093/nar/gkt1111

Patterson, J. E., Sweeney, A. H., Simms, M., Carley, N., Mangi, R., Sabetta, J., et al. (1995). An analysis of 110 serious enterococcal infections. Epidemiology, antibiotic susceptibility, and outcome. Medicine (Baltimore) 74, 191-200. doi: 10.1097/00005792-199507000-00003

Pinholt, M., Larner-Svensson, H., Littauer, P., Moser, C. E., Pedersen, M., Lemming, L. E., et al. (2015). Multiple hospital outbreaks of vanA Enterococcus faecium in Denmark, 2012-13, investigated by WGS, MLST and PFGE. J. Antimicrob. Chemother. 70, 2474-2482. doi: 10.1093/jac/dkv142

Polidori, M., Nuccorini, A., Tascini, C., Gemignani, G., Iapoce, R., Leonildi, A., et al. (2011). Vancomycin-resistant Enterococcus faecium (VRE) bacteremia in infective endocarditis successfully treated with combination 
daptomycin and tigecycline. J. Chemother. Florence Italy 23, 240-241. doi: 10.1179/joc.2011.23.4.240

Raven, K. E., Reuter, S., Gouliouris, T., Reynolds, R., Russell, J. E., Brown, N. M., et al. (2016). Genome-based characterization of hospital-adapted Enterococcus faecalis lineages. Nat. Microbiol. 15033. doi: 10.1038/nmicrobiol.2015.33

Reuter, S., Ellington, M. J., Cartwright, E. J. P., Köser, C. U., Török, M. E., Gouliouris, T., et al. (2013). Rapid bacterial whole-genome sequencing to enhance diagnostic and public health microbiology. JAMA Intern. Med. 173, 1397-1404. doi: 10.1001/jamainternmed.2013.7734

Rice, L. B., Carias, L. L., Hutton-Thomas, R., Sifaoui, F., Gutmann, L., and Rudin, S. D. (2001). Penicillin-binding protein 5 and expression of ampicillin resistance in Enterococcus faecium. Antimicrob. Agents Chemother. 45, 1480-1486. doi: 10.1128/AAC.45.5.1480-1486.2001

Rice, L. B., Carias, L. L., Rudin, S., Lakticová, V., Wood, A., and Hutton-Thomas, R. (2005). Enterococcus faecium low-affinity pbp5 is a transferable determinant. Antimicrob. Agents Chemother. 49, 5007-5012. doi: 10.1128/AAC.49.12.50075012.2005

Ruiz-Garbajosa, P., Bonten, M. J. M., Robinson, D. A., Top, J., Nallapareddy, S. R., Torres, C., et al. (2006). Multilocus sequence typing scheme for Enterococcus faecalis reveals hospital-adapted genetic complexes in a background of high rates of recombination. J. Clin. Microbiol. 44, 2220-2228. doi: 10.1128/JCM.02596-05

Ruiz-Garbajosa, P., de Regt, M., Bonten, M., Baquero, F., Coque, T. M., Cantón, R., et al. (2012). High-density fecal Enterococcus faecium colonization in hospitalized patients is associated with the presence of the polyclonal subcluster CC17. Eur. J. Clin. Microbiol. Infect. Dis. Off. Publ. Eur. Soc. Clin. Microbiol. 31, 519-522. doi: 10.1007/s10096-011-1342-7

Ruiz-Garbajosa, P., del Campo, R., Coque, T. M., Asensio, A., Bonten, M., Willems, R., et al. (2009). Longer intestinal persistence of Enterococcus faecalis compared to Enterococcus faecium clones in intensive-care-unit patients. J. Clin. Microbiol. 47, 345-351. doi: 10.1128/JCM.01597-08

Sader, H. S., Farrell, D. J., Flamm, R. K., and Jones, R. N. (2014). Daptomycin activity tested against 164457 bacterial isolates from hospitalised patients: summary of 8 years of a Worldwide Surveillance Programme (2005-2012). Int. J. Antimicrob. Agents 43, 465-469. doi: 10.1016/j.ijantimicag.2014.01.018

Salipante, S. J., SenGupta, D. J., Cummings, L. A., Land, T. A., Hoogestraat, D. R., and Cookson, B. T. (2015). Application of whole-genome sequencing for bacterial strain typing in molecular epidemiology. J. Clin. Microbiol. 53, 1072-1079. doi: 10.1128/JCM.03385-14

Sarti, M., Campanile, F., Sabia, C., Santagati, M., Gargiulo, R., and Stefani, S. (2012). Polyclonal diffusion of beta-lactamase-producing Enterococcus faecium. J. Clin. Microbiol. 50, 169-172. doi: 10.1128/JCM.05640-11

Sava, I. G., Heikens, E., Kropec, A., Theilacker, C., Willems, R., and Huebner, J. (2010). Enterococcal surface protein contributes to persistence in the host but is not a target of opsonic and protective antibodies in Enterococcus faecium infection. J. Med. Microbiol. 59, 1001-1004. doi: 10.1099/jmm.0.020578-0

Scheetz, M. H., Knechtel, S. A., Malczynski, M., Postelnick, M. J., and Qi, C. (2008). Increasing incidence of linezolid-intermediate or -resistant, vancomycin-resistant Enterococcus faecium strains parallels increasing linezolid consumption. Antimicrob. Agents Chemother. 52, 2256-2259. doi: 10.1128/AAC.00070-08

Shen, J., Wang, Y., and Schwarz, S. (2013). Presence and dissemination of the multiresistance gene cfr in Gram-positive and Gram-negative bacteria. J. Antimicrob. Chemother. 68, 1697-1706. doi: 10.1093/jac/dkt092

Sievert, D. M., Ricks, P., Edwards, J. R., Schneider, A., Patel, J., Srinivasan, A., et al. (2013). Antimicrobial-resistant pathogens associated with healthcareassociated infections: summary of data reported to the National Healthcare Safety Network at the Centers for Disease Control and Prevention, 2009-2010. Infect. Control Hosp. Epidemiol. 34, 1-14. doi: 10.1086/ 668770

Silva-Del Toro, S. L., Greenwood-Quaintance, K. E., and Patel, R. (2016). In vitro activity of tedizolid against linezolid-resistant staphylococci and enterococci. Diagn. Microbiol. Infect. Dis. 85, 102-104. doi: 10.1016/j.diagmicrobio.2016.02.008

Simner, P. J., Adam, H., Baxter, M., McCracken, M., Golding, G., Karlowsky, J. A., et al. (2015). Epidemiology of vancomycin-resistant enterococci in Canadian hospitals (CANWARD study, 2007 to 2013). Antimicrob. Agents Chemother. 59, 4315-4317. doi: 10.1128/AAC.00384-15
Solheim, M., Aakra, A., Snipen, L. G., Brede, D. A., and Nes, I. F. (2009). Comparative genomics of Enterococcus faecalis from healthy Norwegian infants. BMC Genomics 10:194. doi: 10.1186/1471-2164-10-194

Stobberingh, E., Van Den Bogaard, A., London, N., Driessen, C., Top, J., and Willems, R. (1999). Enterococci with glycopeptide resistance in turkeys, turkey farmers, turkey slaughterers, and (sub)urban residents in the south of The Netherlands: evidence for transmission of vancomycin resistance from animals to humans? Antimicrob. Agents Chemother. 43, 2215-2221.

Sydnor, E. R. M., and Perl, T. M. (2011). Hospital epidemiology and infection control in acute-care settings. Clin. Microbiol. Rev. 24, 141-173. doi: 10.1128/CMR.00027-10

Tannock, G. W., and Cook, G. (2002). "Enterococci as members of the Intestinal microflora of humans," in The Enterococci: Pathogenesis, Molecular Biology, and Antibiotic Resistance, ed. M. S. Gilmore (Washington, DC: ASM Press), 101-132.

Tedim, A. P., Ruiz-Garbajosa, P., Corander, J., Rodríguez, C. M., Cantón, R., Willems, R. J., et al. (2015). Population biology of intestinal Enterococcus isolates from hospitalized and nonhospitalized individuals in different age groups. Appl. Environ. Microbiol. 81, 1820-1831. doi: 10.1128/AEM. 03661-14

Thomas, J. C., Zhang, L., and Robinson, D. A. (2014). Differing lifestyles of Staphylococcus epidermidis as revealed through Bayesian clustering of multilocus sequence types. Infect. Genet. Evol. J. Mol. Epidemiol. Evol. Genet. Infect. Dis. 22, 257-264. doi: 10.1016/j.meegid.2013.06.020

Tomayko, J. F., Zscheck, K. K., Singh, K. V., and Murray, B. E. (1996). Comparison of the beta-lactamase gene cluster in clonally distinct strains of Enterococcus faecalis. Antimicrob. Agents Chemother. 40, 1170-1174.

Top, J., Sinnige, J. C., Majoor, E. A., Bonten, M. J., Willems, R. J., and van Schaik, W. (2011). The Recombinase IntA is required for excision of espcontaining ICEEfm1 in Enterococcus faecium. J. Bacteriol. 193, 1003-1006. doi: 10.1128/JB.00952-10

Top, J., Willems, R., and Bonten, M. (2008). Emergence of CC17 Enterococcus faecium: from commensal to hospital-adapted pathogen. FEMS Immunol. Med. Microbiol. 52, 297-308. doi: 10.1111/j.1574-695X.2008.00383.x

Tran, T. T., Panesso, D., Gao, H., Roh, J. H., Munita, J. M., Reyes, J., et al. (2013a). Whole-genome analysis of a daptomycin-susceptible Enterococcus faecium strain and its daptomycin-resistant variant arising during therapy. Antimicrob. Agents Chemother. 57, 261-268. doi: 10.1128/AAC.01454-12

Tran, T. T., Panesso, D., Mishra, N. N., Mileykovskaya, E., Guan, Z., Munita, J. M., et al. (2013b). Daptomycin-resistant Enterococcus faecalis diverts the antibiotic molecule from the division septum and remodels cell membrane phospholipids. mBio 4:e00281. doi: 10.1128/mBio.00281-13

Turner, K. M. E., Hanage, W. P., Fraser, C., Connor, T. R., and Spratt, B. G. (2007). Assessing the reliability of eBURST using simulated populations with known ancestry. BMC Microbiol. 7:30. doi: 10.1186/1471-2180-7-30

Ubeda, C., Taur, Y., Jenq, R. R., Equinda, M. J., Son, T., Samstein, M., et al. (2010). Vancomycin-resistant Enterococcus domination of intestinal microbiota is enabled by antibiotic treatment in mice and precedes bloodstream invasion in humans. J. Clin. Invest. 120, 4332-4341. doi: 10.1172/JCI43918

Uttley, A. H., Collins, C. H., Naidoo, J., and George, R. C. (1988). Vancomycinresistant enterococci. Lancet Lond. Engl. 332, 57-58. doi: 10.1016/S01406736(88)91037-9

van den Bogaard, A. E., Bruinsma, N., and Stobberingh, E. E. (2000). The effect of banning avoparcin on VRE carriage in The Netherlands. J. Antimicrob. Chemother. 46, 146-148. doi: 10.1093/jac/46.1.146

van Hal, S. J., Ip, C. L. C., Ansari, M. A., Wilson, D. J., Espedido, B. A., Jensen, S. O., et al. (2016). Evolutionary dynamics of Enterococcus faecium reveals complex genomic relationships between isolates with independent emergence of vancomycin resistance. Microb. Genomics 2:48. doi: 10.1099/mgen.0. 000048

van Schaik, W., Top, J., Riley, D. R., Boekhorst, J., Vrijenhoek, J. E., Schapendonk, C. M., et al. (2010). Pyrosequencing-based comparative genome analysis of the nosocomial pathogen Enterococcus faecium and identification of a large transferable pathogenicity island. BMC Genomics 11:239. doi: 10.1186/14712164-11-239

Van Tyne, D., and Gilmore, M. S. (2014). Friend turned foe: evolution of enterococcal virulence and antibiotic resistance. Annu. Rev. Microbiol. 68, 337-356. doi: 10.1146/annurev-micro-091213-113003 
Via, S. (2012). Divergence hitchhiking and the spread of genomic isolation during ecological speciation-with-gene-flow. Philos. Trans. R. Soc. Lond. B. Biol. Sci. 367, 451-460. doi: 10.1098/rstb.2011.0260

Wang, Y., Lv, Y., Cai, J., Schwarz, S., Cui, L., Hu, Z., et al. (2015). A novel gene, optrA, that confers transferable resistance to oxazolidinones and phenicols and its presence in Enterococcus faecalis and Enterococcus faecium of human and animal origin. J. Antimicrob. Chemother. 70, 2182-2190. doi: $10.1093 / \mathrm{jac} / \mathrm{dkv} 116$

Weigel, L. M., Donlan, R. M., Shin, D. H., Jensen, B., Clark, N. C., McDougal, L. K., et al. (2007). High-level vancomycin-resistant Staphylococcus aureus isolates associated with a polymicrobial biofilm. Antimicrob. Agents Chemother. 51, 231-238. doi: 10.1128/AAC.00576-06

Werner, G., Coque, T. M., Franz, C. M. A. P., Grohmann, E., Hegstad, K., Jensen, L., et al. (2013). Antibiotic resistant enterococci-tales of a drug resistance gene trafficker. Int. J. Med. Microbiol. IJMM 303, 360-379. doi: 10.1016/j.ijmm.2013.03.001

Werner, G., Gfrörer, S., Fleige, C., Witte, W., and Klare, I. (2008). Tigecyclineresistant Enterococcus faecalis strain isolated from a German intensive care unit patient. J. Antimicrob. Chemother. 61, 1182-1183. doi: 10.1093/jac/dkn065

Willems, R. J., Homan, W., Top, J., van Santen-Verheuvel, M., Tribe, D., Manzioros, X., et al. (2001). Variant esp gene as a marker of a distinct genetic lineage of vancomycin-resistant Enterococcus faecium spreading in hospitals. Lancet 357, 853-855. doi: 10.1016/S0140-6736(00)04205-7

Willems, R. J., Top, J., van Den Braak, N., van Belkum, A., Endtz, H., Mevius, D., et al. (2000). Host specificity of vancomycin-resistant Enterococcus faecium. J. Infect. Dis. 182, 816-823. doi: 10.1086/315752

Willems, R. J., Top, J., van den Braak, N., van Belkum, A., Mevius, D. J., Hendriks, G., et al. (1999). Molecular diversity and evolutionary relationships of Tn1546-like elements in enterococci from humans and animals. Antimicrob. Agents Chemother. 43, 483-491.

Willems, R. J., Top, J., van Santen, M., Robinson, D. A., Coque, T. M., Baquero, F., et al. (2005). Global spread of vancomycin-resistant Enterococcus faecium from distinct nosocomial genetic complex. Emerg. Infect. Dis. 11, 821-828. doi: $10.3201 / 1106.041204$
Willems, R. J. L., Top, J., van Schaik, W., Leavis, H., Bonten, M., Sirén, J., et al. (2012). Restricted gene flow among hospital subpopulations of Enterococcus faecium. mBio 3:e151. doi: 10.1128/mBio.00151-12

Woodford, N., Adebiyi, A. M., Palepou, M. F., and Cookson, B. D. (1998). Diversity of VanA glycopeptide resistance elements in enterococci from humans and nonhuman sources. Antimicrob. Agents Chemother. 42, 502-508.

Xu, X., Lin, D., Yan, G., Ye, X., Wu, S., Guo, Y., et al. (2010). vanM, a new glycopeptide resistance gene cluster found in Enterococcus faecium. Antimicrob. Agents Chemother. 54, 4643-4647. doi: 10.1128/AAC.01710-09

Zhang, X., Paganelli, F. L., Bierschenk, D., Kuipers, A., Bonten, M. J. M., Willems, R. J. L., et al. (2012). Genome-wide identification of ampicillin resistance determinants in Enterococcus faecium. PLoS Genet. 8:e1002804. doi: 10.1371/journal.pgen.1002804

Zhang, X., Top, J., de Been, M., Bierschenk, D., Rogers, M., Leendertse, M., et al. (2013). Identification of a genetic determinant in clinical Enterococcus faecium strains that contributes to intestinal colonization during antibiotic treatment. J. Infect. Dis. 207, 1780-1786. doi: 10.1093/infdis/ jit076

Zorzi, W., Zhou, X. Y., Dardenne, O., Lamotte, J., Raze, D., Pierre, J., et al. (1996). Structure of the low-affinity penicillin-binding protein 5 PBP5fm in wild-type and highly penicillin-resistant strains of Enterococcus faecium. J. Bacteriol. 178, 4948-4957.

Conflict of Interest Statement: The authors declare that the research was conducted in the absence of any commercial or financial relationships that could be construed as a potential conflict of interest.

Copyright (C) 2016 Guzman Prieto, van Schaik, Rogers, Coque, Baquero, Corander and Willems. This is an open-access article distributed under the terms of the Creative Commons Attribution License (CC BY). The use, distribution or reproduction in other forums is permitted, provided the original author(s) or licensor are credited and that the original publication in this journal is cited, in accordance with accepted academic practice. No use, distribution or reproduction is permitted which does not comply with these terms. 